\title{
REVIEWS
}

\section{Targeting voltage-gated calcium channels in neurological and psychiatric diseases}

\section{Gerald W. Zamponi}

Abstract | Voltage-gated calcium channels are important regulators of brain, heart and muscle functions, and their dysfunction can give rise to pathophysiological conditions ranging from cardiovascular disorders to neurological and psychiatric conditions such as epilepsy, pain and autism. In the nervous system, calcium channel blockers have been used successfully to treat absence seizures, and are emerging as potential therapeutic avenues for pathologies such as pain, Parkinson disease, addiction and anxiety. This Review provides an overview of calcium channels as drug targets for nervous system disorders, and discusses potential challenges and opportunities for the development of new clinically effective calcium channel inhibitors.

\section{Calcium channels \\ A group of membrane proteins that allow entry of calcium into cells.}

Alternative splicing A process by which one gene can create different variants of one protein.

Parkinson disease A neurological disorder caused by a loss of dopaminergic neurons.

Epilepsy

A neurological disorder in which patients present with seizures.
Department of Physiology and Pharmacology, Hotchkiss Brain Institute and Alberta Children's Hospital Research Institute, Cumming School of Medicine, University of Calgary, Calgary T2N 4N1, Canada. zamponi@ucalgary.ca
Calcium ions are critical mediators of cell signalling by virtue of their electrogenic functions (that is, calciuminduced changes in membrane potential $)^{1}$ and through their roles as intracellular messengers (that is, through activation of calcium-dependent enzymes) ${ }^{2}$. Increases in intracellular calcium that are mediated either by their release from internal calcium stores, or via entry of calcium ions across the plasma membrane, have been linked to a wide spectrum of physiological processes, including neurotransmitter/hormone release ${ }^{3}$, activation of gene transcription ${ }^{4,5}$, and muscle contraction ${ }^{6}$. Consequently, processes that result in compromised calcium signalling can lead to a range of pathophysiological conditions, such as hypertension, cardiac hypertrophy and a vast array of neurological problems ${ }^{7}$. One of the key mediators of calcium entry from the extracellular space are voltage-gated calcium channels - a family of membrane proteins that open in response to membrane depolarization to permit the influx of calcium along its electrochemical gradient. The mammalian nervous system expresses nine different types of calcium channels that have specific functions and subcellular distributions ${ }^{8}$, with additional functional diversity arising from alternative splicing events ${ }^{9}$ and specific association with different types of ancillary subunits and regulatory proteins ${ }^{10}$. Calcium channel dysregulation has been linked to a number of disorders, including pain, Parkinson disease and epilepsy ${ }^{7}$. Furthermore, mutations in calcium channel genes in human patients have been associated with pathologies such as seizure disorders, migraine and ataxia ${ }^{11,12}$. Consequently, calcium channels are considered important targets for therapeutic intervention.
A number of drugs that block voltage-gated calcium channels are in clinical use (TABLE 1), with many other calcium channel blockers being in preclinical or early clinical development. This Review article highlights the role of these channels in neuronal function and assesses their growing potential as drug targets for nervous system disorders.

\section{Subtypes and structure of calcium channels}

Before the advent of molecular cloning techniques, calcium channels in the heart and brain were classified based on their voltage-dependent activation into either high voltage-activated (HVA) or low voltage-activated (LVA; also known as T-type) channels ${ }^{13}$, with the latter requiring smaller membrane depolarizations to open. HVA channels are subdivided further based on their pharmacological and biophysical characteristics into L-, P-, Q- and R-types ${ }^{14}$. We now know that these different subtypes of HVA and LVA channels correspond to a total of ten different Caval subunits that are encoded in the mammalian genome. Three of these Cava1 subunits (Cav3.1, Cav3.2 and Cav3.3) comprise the family of T-type calcium channels, and their expression in the plasma membrane is sufficient to form functional channel proteins ${ }^{15}$. There are two major families of HVA Cava1 subunits: the Cav1 family encodes four different types of L-type channels (Cav1.1 to Cav1.4), whereas the Cav2 family encompasses P/Q-type (Cav2.1), N-type (Cav2.2) and R-type (Cav2.3) 7 channels, with P- and Q-type channels being distinguished by alternative splicing and channel subunit composi$\operatorname{tion}^{16,17}$. Each of these al subunits is a large $(\sim 200 \mathrm{kDa})$ protein composed of four homologous transmembrane 
Table 1 | Selected calcium channel blockers for the treatment of neurological or psychiatric conditions

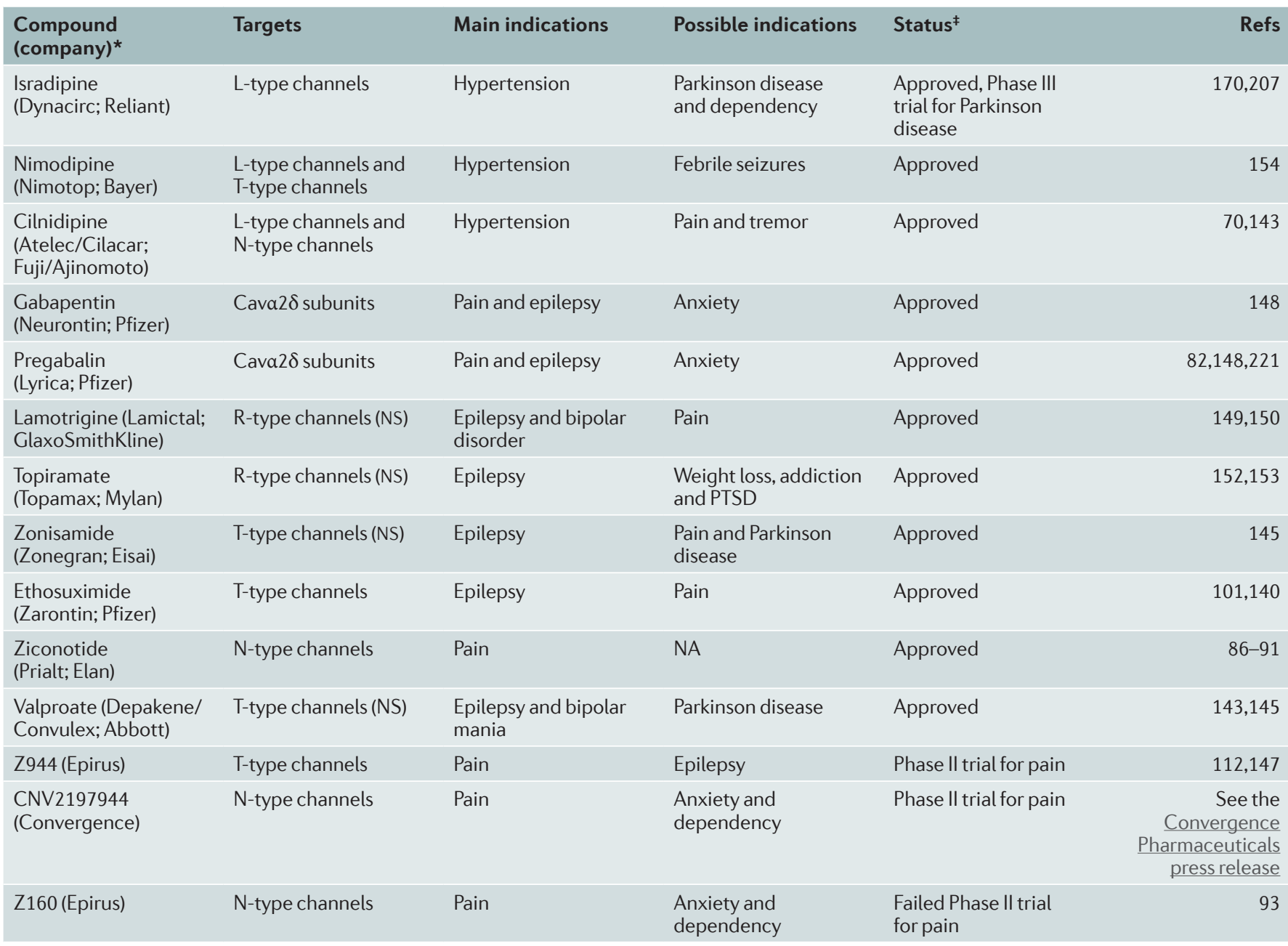

NA, not applicable; NS, not specified; PTSD, post-traumatic stress disorder. ${ }^{*}$ The names of distributing pharmaceutical companies are shown in parentheses, although several of the compounds are now available as generic drugs. ${ }^{*}$ Note that Z944 and CV2197944 are in clinical trials and not yet approved.

domains, each containing six transmembrane helices plus a pore loop (p-loop) motif (FIG. 1) that forms the permeation pathway of the channel and ensures selectivity for calcium ions over monovalent ions ${ }^{7}$. Each of the membrane domains also contains a voltage sensor motif that allows the channel to open in response to membrane depolarization ${ }^{18}$. The amino- and carboxy-terminal regions and the linkers between the four membrane domains face the cytoplasm and serve as important targets for second messenger regulation of channel function ${ }^{7}$. The majority of known drug interaction sites with voltagegated calcium channels lie either within the permeation pathway, or in channel regions that closely surround the pore of the channel, such as the fifth and sixth transmembrane helices $^{19-21}$ (FIG. 1). All of the HVA Caval isoforms require co-assembly with ancillary calcium channel subunits to obtain properly functioning channels ${ }^{22}$.

Cav $\beta$ subunits are cytoplasmic proteins that associate with the domain I-II linker region of the Caval subunit ${ }^{23}$. The Cava $2 \delta$ subunits undergo proteolytic cleavage into Cava 2 and $\operatorname{Cav} \delta$ fragments that are then re-linked via disulphide bonds, with the Cava2 portion being entirely exposed to the extracellular milieu and the Cav $\delta$ portion acting as a membrane anchor ${ }^{24} \cdot \operatorname{Cav} \beta$ and Cava $2 \delta$ subunits are each encoded by four different genes $^{7}$. Their main functions are to regulate the biophysical characteristics of the channels and, more importantly, the export of the channel complex from the endoplasmic reticulum and the stability of the channel in the plasma membrane ${ }^{25,26}$. Some HVA calcium channels also contain a Cav $\gamma$ subunit (most notably the skeletal muscle L-type channels), a transmembrane protein encoded by as many as eight different genes and with poorly understood function ${ }^{27}$. Each of the major calcium channel subunits is known to undergo alternative splicing ${ }^{28}$. Between the various splice isoforms and possible combinations of Cava1, $\operatorname{Cav} \beta$ and Cav $\alpha \delta$ subunits, a vast number of different calcium channels with a wide spectrum of functional and pharmacological properties (and potentially specific physiological functions) can be generated. This is a particularly important consideration during the development of calcium channel therapeutics, and it often relies on the heterologous expression of a specific combination of calcium channel subunits in a host cell line. 


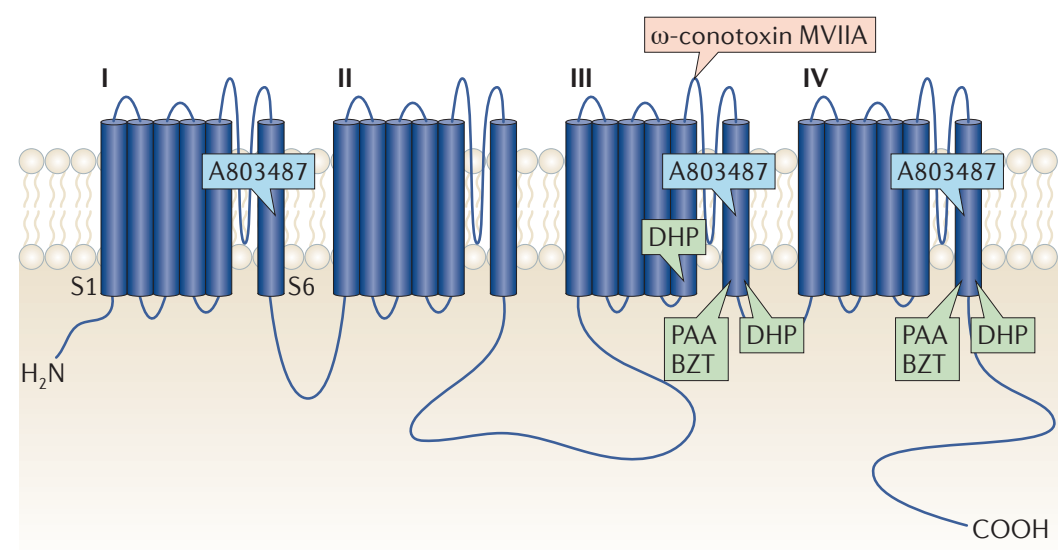

Figure 1 | Locations of drug interaction sites on voltage-gated calcium channels. The transmembrane topology of the pore-forming Cava1 subunit with its four major transmembrane domains (I-IV) is shown, each of which contains six membrane-spanning helices (termed S1-S6), as well as a re-entrant pore loop. Blockers of N-type, T-type and L-type channels are labelled, in red, blue, and green, respectively. Sites of drug interactions are shown. Note that the transmembrane domain IIIS6 and IVS6 regions are hotspots for drug interactions. BZT, benzothiazepine; DHP, dihydropyridine; PAA, phenylalkylamine.

Dihydropyridines

A class of drug molecules that often act on calcium channels.

Phenylalkylamines

A specific class of small organic molecules that block calcium channels.
Key nervous system functions of calcium channels So why do vertebrates need so many types of calcium channels? Part of the answer may lie in the notion that different calcium channel subtypes fulfil specific physiological roles, and different variants of the same calcium channel subtype may serve as a fine-tuning mechanism not only because of their particular biophysical characteristics but also because of their differential regulation. The nervous system expresses nine of the ten major calcium channel isoforms, with the skeletal-musclespecific Cav1.1 channels being the only isoforms that are absent ${ }^{29}$. Different calcium channel isoforms often support multiple physiological roles, and those that are particularly pertinent are discussed here. Cav1.2 channels are expressed in most types of neurons. They are often localized on cell bodies and at dendritic regions ${ }^{30}$, and are thought to be important for the activation of calcium-dependent enzymes ${ }^{31}$, the activation of calciumactivated potassium channels ${ }^{32}$ and the initiation of calcium-dependent gene transcription events ${ }^{4}$. Cav1.3 channels show a similar subcellular distribution to that observed with Cav1.2 (REF. 30). As well as contributing to postsynaptic activity, these channels are expressed at ribbon synapses of cochlear hair cells where they have a critical role in auditory transmission ${ }^{33}$. Indeed, mice lacking Cav1.3 channels are deaf, as are human patients with null mutations in the Cav1.3-encoding gene CACNA1D ${ }^{34,35}$. Cav1.4 channels are predominantly expressed in rod photoreceptors where they control glutamate release from ribbon synapses. Consequently, Cav1.4-null mice are blind ${ }^{36}$ and loss of Cav1.4 expression in humans gives rise to night blindness ${ }^{37}$.

Cav2.1 and Cav2.2 channels are expressed at presynaptic nerve terminals where they are closely associated with the neurotransmitter release machinery ${ }^{3,38}$. Some synapses are designed to accommodate specific complements of each of these two channel subtypes ${ }^{39}$, whereas others such as primary afferent nerve terminals in the spinal dorsal horn almost exclusively express Cav2.2 channels. However, these two channel subtypes are not created equally. Whereas Cav2.2-null mice are viable and display hyposensitivity to pain ${ }^{40}$, Cav2.1-null mice experience seizures and cerebellar ataxia ${ }^{41}$. This suggests that Cav2.1 channels may have a key role besides neurotransmitter release; indeed, Cav2.1 channels have been associated with gene transcription of synaptic proteins such as syntaxin $1 \mathrm{~A}^{42}$. In humans, gain-of-function mutations in Cav2.1 channels can give rise to familial hemiplegic migraine ${ }^{43}$, whereas loss-of-function mutations or polyglutamine expansions in the Cav2.1 C-terminal lead to conditions such as episodic ataxia type $\mathrm{II}^{44}$ and spinocerebellar ataxia 6 (REF. 45), respectively. Conversely, mutations in Cav2.2 have been associated with myoclonus dystonia-like syndrome, which, interestingly, is accompanied by cardiac arrhythmias, perhaps owing to the role of $\mathrm{N}$-type channels in the sympathetic nervous system $^{46}$. Cav2.3 channels are thought to contribute to neurotransmitter release at a subset of central nervous system (CNS) synapses ${ }^{47,48}$, as well as helping to regulate neuronal excitability. Consequently, Cav2.3-null mice are resistant to certain types of pharmacologically induced seizures ${ }^{49}$.

The three members of the Cav3 channel family have important roles in regulating neuronal firing, which is closely linked to their specific gating characteristics ${ }^{1,50}$. Their low threshold of voltage activation, coupled with their tonic inactivation at typical resting membrane potential, underlies the rebound bursting phenomenon seen in many types of neurons ${ }^{51}$. In this context, it is important to note that different types of Cav3 channels differentially regulate neuronal firing behaviour ${ }^{51}$, and this diversity is further increased by the existence of different Cav3 splice variants ${ }^{52}$. Finally, there is recent evidence that Cav3 channels can partake in low-threshold exocytosis, perhaps owing to their interactions with synaptic proteins such as syntaxin $1 \mathrm{~A}^{53}$.

Discussed above are just some of the most important physiological roles of these various calcium channel subtypes, and this is by no means a comprehensive account of all calcium channel functions in the nervous system. A recent review ${ }^{7}$ on this topic provides a more in-depth discussion. This high-level summary does, however, provide appropriate context and background for the ensuing sections in this article, such as the potential of these channels as established and prospective drug targets.

\section{Identifying new calcium channel therapeutics}

Fifty years ago, research on the effects of verapamil and prenylamine on excitation-contraction coupling led to the discovery of several classes of calcium blockers (originally termed calcium antagonists) ${ }^{54}$. Much of the initial work on these agents focused on L-type calcium channels and revealed that these channels have multiple drug interaction sites for compound classes such as dihydropyridines, phenylalkylamines and benzothiazepines ${ }^{55}$. As these drug interaction sites are non-competitively coupled, this enabled the use of high-throughput radioligand displacement assays to identify new compounds 
that interacted with these channels ${ }^{56}$. These early studies involved native channel complexes from muscle or brain tissue $^{57}$. The cloning of various calcium channel isoforms allowed the generation of stable cell lines that expressed one specific calcium channel subtype and that could be loaded with a calcium indicator dye $e^{58,59}$. Membrane depolarization induced by potassium chloride $(\mathrm{KCl})$ leads to channel opening, and the effects of compounds on the associated rise in calcium fluorescence can be used to determine their ability to block the channels ${ }^{58,59}$. Automation of this assay allows the high-throughput screening of large compound libraries in a short time frame. Moreover, unlike the early radioligand studies, this approach is applicable to all major calcium channel isoforms and does not require the availability of tritiated drug compounds ${ }^{60}$.

There is a drawback, however, in the use of a single $\mathrm{KCl}$ depolarization, as this approach cannot easily identify compounds with strong use-dependence ${ }^{61}$, which is a desirable quality in compounds such as anti-arrhythmics and anticonvulsants. As many use-dependent compounds interact preferentially with inactivated channels, one way to use fluorescence assays to identify such types of blockers is to regulate the membrane potential of the cells by bathing them in slightly elevated $\mathrm{KCl}$ levels before applying a larger $\mathrm{KCl}$ depolarization that opens the channels ${ }^{62,63}$. The development of high-throughput automated patch clamp systems has greatly facilitated the identification of drug compounds with specific kinetic properties $^{61,64}$; however, this additional information comes at the expense of throughput.

Techniques such as photoaffinity labelling ${ }^{65}$, coupled with site-directed mutagenesis, have been used successfully to identify major drug interaction sites on L-type calcium channels at the single amino acid level (FIG. 1). In some cases, knowledge of drug interactions with other classes of ion channels (such as sodium channels) has been used to identify drug interaction sites on voltage-gated calcium channels, such as T-type channels. For example, key amino acid residues that comprise the local anaesthetic interaction site in sodium channels are conserved in T-type calcium channels, and mutagenesis of these residues reduces the interaction of these channels with local anaesthetic-like compounds ${ }^{19}$. Curiously, the S6 regions in domains III and IV of the Caval subunit appear to be hotspots for drug interaction sites in both L-type and T-type channels (FIG. 1), perhaps because these channel structures are linked to the inactivation-gating machinery and line the inner vestibule of the channel pore ${ }^{66}$. When coupled with homology modelling ${ }^{67}$, such knowledge of the molecular makeup of drug interaction sites could potentially provide important insights into drug structure requirements for calcium channel inhibition and thus enable a rational approach towards drug design ${ }^{68}$.

One of the challenges in designing and developing small organic calcium channel blockers is the relatively high sequence conservation among different members of the calcium channel family and sequence similarities to other members of the voltage-gated ion channel superfamily ${ }^{8}$. This makes it very difficult to identify compounds with high affinity and high selectivity for one particular calcium channel target. Indeed, several dihydropyridines (a class of compounds commonly thought of as being selective for L-type channels) have been shown to block other calcium channel subtypes such as T-type and N-type channels, in some cases even preferentially over L-type channels ${ }^{69-71}$.

Despite decades of drug discovery efforts, only a few bona fide calcium channel therapeutics other than dihydropyridines have entered the clinic. This underscores the immense challenge in finding compounds that: have high affinity; have high target selectivity (especially over HERG channels); effectively cross the blood-brain barrier; have the appropriate physicochemical properties; are not rapidly metabolized; and are non-toxic. The ensuing sections provide an overview of the therapeutic potential of calcium channel blockers in various nervous system disorders and a summary of existing drugs targeting calcium channels (TABLE 1), as well as compounds that are currently in the drug discovery pipeline.

\section{Calcium channel inhibitors as pain therapeutics}

Pain stimuli are detected by peripheral nociceptors that innervate the skin and organ tissues. Action potentials then propagate along the primary afferent fibre to synaptic nerve terminals in the spinal dorsal horn, where excitatory synaptic transmission then activates neurons that project to higher brain centres where pain is perceived $^{72}$ (FIG. 2). Voltage-gated calcium channels are known to factor prominently in this afferent pathway in two principal ways ${ }^{73}$. Cav3.2 T-type calcium channels are important regulators of afferent fibre excitability, whereas Cav2.2 and, to a lesser extent, Cav3.2 channels both contribute to neurotransmission at dorsal horn synapses $^{74}$ (FIG. 2). Both calcium channel subtypes are upregulated under chronic pain conditions ${ }^{75-77}$; conversely, inhibiting Cav2.2 and/or Cav3.2 channel activity in rodents has been shown to mediate analgesia ${ }^{74}$.

For therapeutic purposes, Cav2.2 channels can be targeted in multiple ways. First, Cav2.2 channels are under the powerful control of several $G$ protein-coupled receptors, including $\mathrm{GABA}_{\mathrm{B}}$ ( $\gamma$-aminobutyric acid, type $\mathrm{B}$ ) receptors and various members of the opioid receptor family ${ }^{78}$. Indeed, the clinically used $\mu$-opioid receptor agonist morphine inhibits Cav2.2 channel activity and thus neurotransmitter release from primary afferent neurons ${ }^{79}$. However, although it is a potent analgesic, morphine has numerous side effects such as respiratory depression and constipation ${ }^{80}$. Therefore, receptorindependent means of inhibiting Cav2.2 channels are desirable. The gabapentinoids gabapentin (Neurontin; Pfizer) and pregabalin (Lyrica; Pfizer) inhibit synaptic transmission mediated by the Cav2.2 channel through a very different mechanism that involves interactions with the Cava $2 \delta$ subunit. These subunits are upregulated in chronic pain states ${ }^{81}$, leading to increased Cav2.2 cell surface expression. Treatment with gabapentinoids interferes with Cava $2 \delta$ function, leading to a reduced Cav2.2 calcium channel density in the presynaptic plasma membrane ${ }^{82-84}$. Despite their overall moderate 

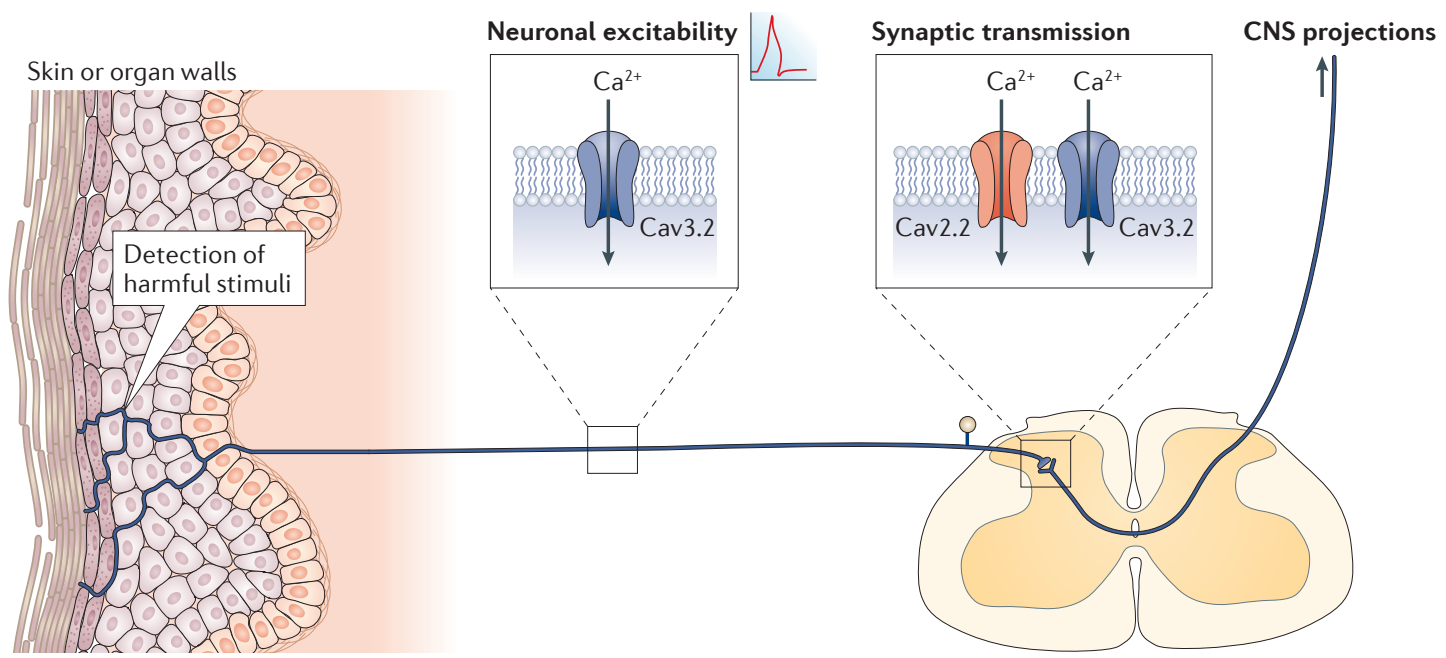

Figure 2 | Role of voltage-gated calcium channels in the primary afferent pain pathway. Harmful stimuli (such as pressure, heat and cold) are detected by nerve endings embedded in the skin or organs, leading to the generation of action potentials that travel along the afferent fibre to synaptic terminals in the spinal dorsal horn, where neurotransmitter release activates postsynaptic neurons that project to the brain. Cav3.2 calcium channels regulate afferent fibre excitability and contribute to calcium influx in synaptic nerve terminals. Cav2.2 channels are located presynaptically where their opening allows calcium entry and leads to neurotransmitter release. CNS, central nervous system.

Neuropathic pain

A chronic pain condition arising from a peripheral nerve injury.

\section{Ziconotide}

A synthetic version of $\omega$-conotoxin MIIA that is used for pain treatment.

\section{Z160}

A blocker of $\mathrm{N}$-type calcium channels that was explored as an analgesic.

TROX-1

A blocker of N-type calcium channels that was developed by Merck.

\section{Neuropathy}

A disease or dysfunction of peripheral nerves.

Ethosuximide

A type of anti-epileptic drug that acts on T-type calcium

channels.

Z944

A drug molecule that potently blocks T-type calcium channels. efficacy, these compounds are important therapeutic choices for treating neuropathic pain and have become blockbuster drugs ${ }^{85}$.

A direct inhibitor of Cav2.2 calcium channel activity is also currently used in the clinic. Ziconotide (Prialt; Elan) is a synthetic version of $\omega$-conotoxin MVIIA, a 26-amino-acid peptide isolated from the venom of the Conus magus fish-hunting snail. Ziconotide is a highly selective pore blocker of Cav2.2 calcium channels, and when delivered intrathecally (this peptide does not cross the blood-brain barrier) it mediates analgesia ${ }^{86-88}$. Besides the requirement for delivery via an implanted minipump and its limited indication for drug-resistant cancer pain, it also suffers from a narrow therapeutic window and thus has a variety of potential side effects that include memory loss and unruly behaviour ${ }^{87,89-91}$. As a physical blocker of the Cav2.2 channel pore, ziconotide does not exhibit use-dependent blocking properties $^{92}$ and therefore does not preferentially target Cav2.2 channels in hyperactive neurons. Several small organic Cav2.2 channel inhibitors, however, have been shown to mediate strong use-dependent inhibition of Cav2.2 channels in the nanomolar range. This includes Z160 (also known as NMED-160 or NP-118809; Epirus), a compound that mediates potent analgesia in several animal models of pain ${ }^{93}$. Unfortunately (and very much surprisingly) this compound failed two different Phase II clinical trials for lack of efficacy, for reasons that are unclear. Other state-dependent Cav2.2 channel blockers that are currently in preclinical development include compounds such as TROX-1 (Merck) ${ }^{94}$ and CNV2197944 (Convergence Pharmaceuticals, now held by its sister company Calchan Ltd), which has successfully completed Phase I clinical trials and is now in Phase II trials for postherpetic neuralgia and painful diabetic neuropathy (see the Convergence Pharmaceuticals press release for further information). Several other classes of small organic Cav2.2 channel blockers with efficacy in animal models of pain have been reported in the literature (see REFS 95-99), some of which also target T-type calcium channels ${ }^{100}$.

This latter point is pertinent, as T-type calcium channels are also emerging as suitable targets for analgesics. Following early studies showing that intrathecal delivery of the T-type channel inhibitor ethosuximide (Zarontin; Pfizer) mediates analgesia ${ }^{101}$, it was shown that intrathecal delivery of small interfering RNA (siRNA) against Cav3.2 channels, but not other T-type calcium channel isoforms, protected against inflammatory and neuropathic pain ${ }^{102}$. This led to the discovery of a number of different scaffolds for high affinity T-type calcium channel inhibitors with efficacy in a variety of pain models after either subdural or systemic (intraperitoneal) delivery ${ }^{103-108}$. Notably, this included a novel class of dihydropyridine blockers that preferentially inhibited Cav3.2 channels over L-type channels, as well as several compounds that were derived from cannabinoid receptor ligands. This is in accordance with the observation that endocannabinoids such as anandamide have been found to potently block T-type channels ${ }^{109,110}$. A mixed blocker of Cav3 and Nav1.7 sodium channels, Z123212, has been described as a potent analgesic in rodents ${ }^{111}$. This compound interacts preferentially with the slow inactivated state of these channels, thereby giving rise to strong use-dependent inhibition. Although most of these compounds are still in preclinical development, Z944 (Epirus Pharmaceuticals) ${ }^{112}$, a potent and statedependent T-type calcium channel inhibitor, completed Phase I clinical trials for pain and is being advanced to Phase II trials. It remains to be determined whether the analgesic actions of T-type channel inhibitors occur via inhibition of synaptic activity in the dorsal horn, or 
by alterations of afferent fibre excitability ${ }^{74}$. Interestingly, a small randomized trial evaluating the Cav3.2 channel blocker ABT-639 (AbbVie) as a therapeutic for diabetic pain revealed a lack of efficacy compared to placebo ${ }^{113}$. This does not, however, invalidate the potential of T-type calcium channel inhibitors as analgesics.

Finally, there is emerging evidence that Cav2.3 (R-type) calcium channels may be involved in pain signalling. Intrathecal delivery of the Cav2.3 inhibitor SNX-482 (a peptide derived from the venom of a Tarantula species) inhibits formalin-induced pain and neuropathic pain in rodents ${ }^{114,115}$. This is consistent with the expression of these channels in dorsal root ganglion (DRG) neurons and in the spinal dorsal horn ${ }^{116}$, as well as with data showing that Cav2.3-null mice display pain hyposensitivity ${ }^{117}$. However, it should be noted that this compound also inhibits L-type calcium channels, albeit at higher concentrations than those needed for Cav2.3 channel block ${ }^{118}$. Polymorphisms in the gene encoding Cav2.3 have been linked to changes in fentanyl sensitivity in patients undergoing surgery ${ }^{119}$, altogether suggesting that Cav2.3 calcium channels could be explored as potential targets for pain. There is currently no selective small organic inhibitor of Cav2.3 channels, although it should be noted that the $\mathrm{N}$-type channel blocker TROX-1 also mediates inhibition of Cav2.3 channels with about $50 \%$ lower affinity compared with Cav2.2 channels (REF. 94). This compound could thus perhaps form the starting point for the development of a preferential Cav2.3 inhibitor.

Calcium channels as targets for seizure disorders Seizures occur as a result of a combination of hyperexcitability and abnormal synchrony of neurons. Focal seizures typically involve one hemisphere and can arise from injury to a specific brain structure or from a tumour ${ }^{120}$. Conversely, idiopathic seizures are not accompanied by radiological abnormalities, typically involve both hemispheres and can be triggered by more diffuse insults to the brain, such as high fever (that is, febrile seizures), hypoxia, or even oxygen toxicity ${ }^{121}$. They may also arise from genetic abnormalities in a variety of ion channels and receptors, such as voltagegated sodium channels and GABA receptors ${ }^{122-124}$. Absence seizures are one of the hallmarks of idiopathic generalized epilepsy (IGE) and are characterized by brief periods of unresponsiveness and abnormal spike and wave discharges in EEG recordings that reflect hypersynchronous activity of thalamocortical structures ${ }^{125}$. It is thought that the initiation of absence seizures is critically dependent on the activation of T-type calcium channels in thalamocortical neurons and reticular thalamic nucleus neurons (nRT neurons) ${ }^{126}$, which express Cav3.1 and Cav3.2/Cav3.3 calcium channels, respectively (FIG. 3a). The firing of these neurons can be drastically altered by even small changes in T-type channel activity ${ }^{127}$. Furthermore, in several genetic mouse models of absence epilepsy (such as Cav2.1-knockout mice, 'lethargic mice' that lack functional Cav $\beta 4$, and 'stargazer mice', which carry a loss-of-function mutation in the Cav $\gamma 2$ subunit), there is an increase in T-type calcium channel activity in nRT neurons ${ }^{128}$. Along these lines, in the GAERS rat model of absence epilepsy, there is an increase in thalamic T-type channel activity (which is accompanied by increased Cav3.2 mRNA levels) owing to a gain-offunction mutation in Cav3.2 (REF. 129). Interestingly, this gain-of-function mutation is only able to manifest functional changes in a specific Cav3.2 splice isoform that contains exon 25 (which is the predominant splice isoform expressed in the thalamus) ${ }^{129}$.

The role of Cav3.2 channels in seizure genesis is underscored by genetic analysis of human patients with various forms of idiopathic generalized seizures ${ }^{124}$. Mutations in the gene that encodes Cav3.2 (CACNA1H) have been associated with childhood absence epilepsy, juvenile absence epilepsy and juvenile myoclonic epilepsy, among several other types of epilepsy ${ }^{130}$. In excess of thirty different $C A C N A 1 H$ mutations have been identified, and many of them have been introduced into recombinant Cav3.2 channels for electrophysiological analysis. A subset of these mutations was shown to mediate a gain of function in channel gating, with some of the mutations promoting plasma membrane trafficking of the channels ${ }^{131-133}$ (FIG. 3b). These gain-of-function effects may not only affect the electrical excitability of neurons but also alter gene transcription events ${ }^{134}$. Given the findings with the GAERS model, it is important to consider the specific splice variant background that is used for such functional studies, such that they accurately reflect their physiological effects. Cav3.1-overexpressing mice show enhanced thalamocortical network activity and present with pure absence seizures ${ }^{135}$.

Altogether, these findings indicate that enhanced activity or expression of T-type calcium channels in the thalamus increases seizure susceptibility. It thus stands to reason that decreasing the activity or expression of these channels should protect against seizures. Indeed, mice lacking Cav3.1 calcium channels are resistant to baclofen-induced seizures ${ }^{136}$. Furthermore, when crossed with Cav3.1-knockout mice, the seizure abnormalities in several mouse models of absence epilepsy are normalized ${ }^{128}$. Overall, these findings support the idea that targeting Cav3.1 and Cav3.2 channels could be a strategy for mitigating absence seizures.

The role of Cav3.3 channels in the generation of burst firing in nRT neurons is somewhat controversial. On the one hand, Cav3.3 channel activity can give rise to bursting behaviour that fits with that observed in nRT neurons ${ }^{137}$, and this appears to be a critical factor in the generation of sleep spindles ${ }^{138}$. On the other hand, mice that either globally lack Cav3.3 channels, or mice that are selectively deficient for Cav3.3 channels in nRT neurons, appear to show greater susceptibility to pharmacologically induced spike and wave discharges and increased inhibitory synaptic inputs onto thalamocortical neurons ${ }^{139}$. It is currently not clear whether knockout of Cav3.3 could lead to compensatory increases in the expression of other ion channels or receptors that lead to such an increase in the excitability of nRT neurons. Furthermore, owing to the lack of selective Cav3.3 channel blockers, it is not clear whether acute inhibition of these channels mediates effects that 
a

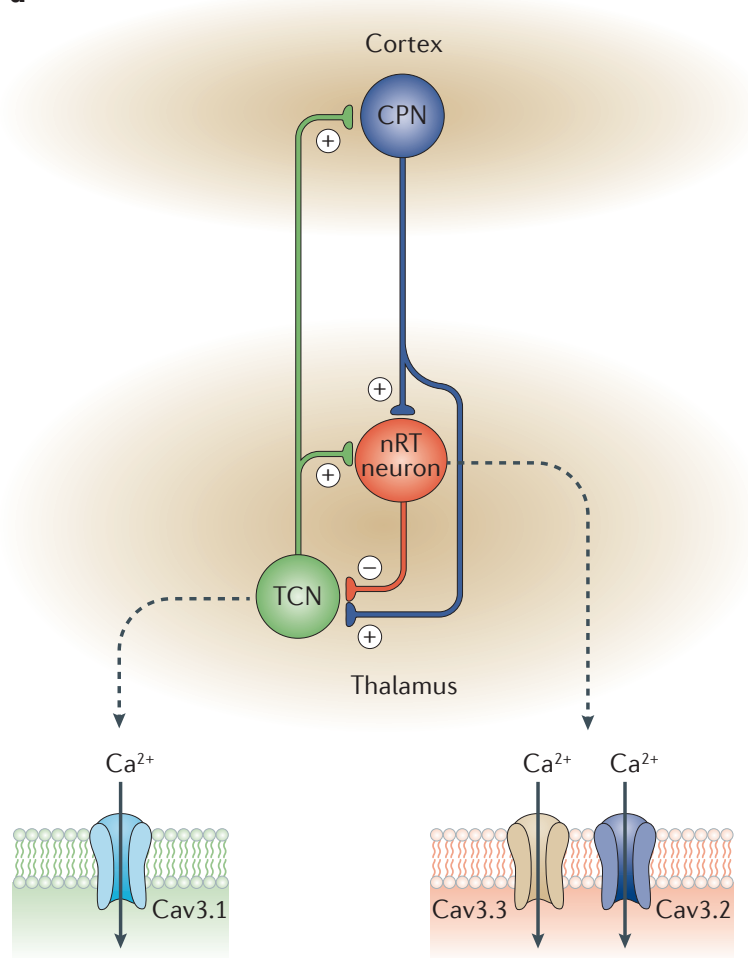

b
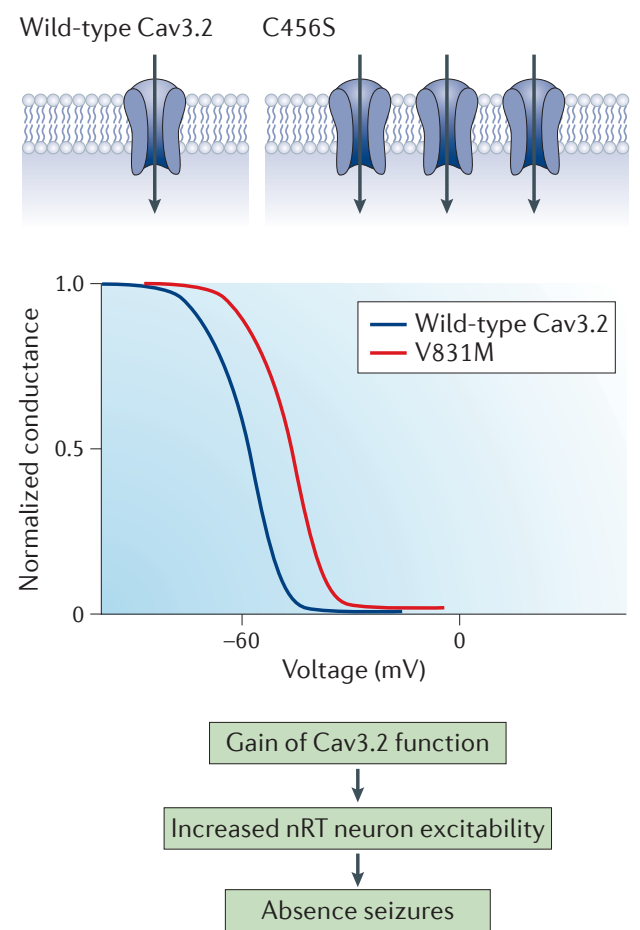

Figure 3 | Role of T-type calcium channels in the thalamocortical circuitry. a | Thalamocortical neurons (TCNs) have excitatory projections to both cortical pyramidal neurons (CPNs) and reticular thalamic nucleus (nRT) neurons. Descending excitatory projections innervate nRT neurons and TCNs, whereas nRT neurons have inhibitory inputs onto thalamocortical cells. The excitability of this network is strongly dependent on T-type calcium channels, with Cav3.1 channels being expressed in TCNs, and Cav3.2 and Cav3.3 channels being expressed in nRT neurons. b | Mutations in Cav3.2 that are found in patients with congenital forms of absence epilepsy increase Cav3.2 channel function. The C456S mutation increases cell surface expression of the channels, whereas the V831M mutation increases channel availability by mediating a depolarizing shift in the steady-state inactivation curve. Both cases result in increased T-type current amplitudes, leading to increased excitability of nRT neurons and thus absence seizures.

\section{Valproate}

An anti-epileptic drug with multiple molecular targets.

Lamotrigine

An anti-epileptic drug with multiple molecular targets. are equivalent to those observed upon deletion of the gene encoding Cav3.3. Nonetheless, when developing T-type calcium channel blockers for therapeutic intervention, this ambiguous role of Cav3.3 channels should be considered.

Ethosuximide is a T-type calcium channel blocker that has been used clinically to treat absence seizures ${ }^{140}$. This compound is a low-affinity (in the submillimolar range) blocker of all three Cav3 channel isoforms, with a preference for inactivated channels, and it gives rise to use-dependent inhibition ${ }^{141}$. The anti-epileptic sodium valproate (Depakene/Convulex; Abbott) has also been described as a T-type channel inhibitor ${ }^{142}$. However, this compound is also known to inhibit other targets such as sodium channels ${ }^{143}$ and histone deacetylases ${ }^{144}$. Along these lines, the multitarget antiepileptic drug zonisamide (Zonegran; Eisai) has also been reported to inhibit T-type channels in the micromolar range, but curiously without any apparent state dependence ${ }^{145}$. Interestingly, there is evidence that this compound also improves pain responses in rodents, further supporting the role of T-type channels in pain signalling (as discussed in the section above $)^{146}$. More recent drug discovery efforts by Zalicus (now Epirus Biopharmaceuticals) have identified small organic molecules (including the aforementioned compound Z944 and a compound termed Z941) that potently inhibit Cav3.2 T-type calcium channels and block seizure activity in the GAERS model ${ }^{147}$. Z944 was also shown to inhibit burst firing in nRT neurons, which is consistent with the critical role of these channels in thalamic neuron excitability. As Z944 is already in clinical testing for pain, this may provide the opportunity for testing this compound in patients with absence seizures.

HVA calcium channels may also be targeted for the treatment of seizures. Gabapentin is used as an anticonvulsant to treat focal and partial seizures ${ }^{148}$. However, given that this compound has the propensity to affect multiple types of HVA channels through its interaction with Cava $2 \delta$ subunits, it is not clear how this compound mediates its clinical effects at the cellular level. The anti-epileptic lamotrigine (Lamictal; GlaxoSmithKline) is also widely used for the treatment of focal and absence seizures, but its mode of action remains incompletely understood ${ }^{149,150}$. This compound blocks transiently expressed R-type Cav2.3 channels in the low micromolar range, with a small effect on Cav3.1 channels ${ }^{151}$. A recent study revealed that the anti-seizure effects of lamotrigine observed in mice are dependent 
on the presence of Cav2.3 channels ${ }^{152}$. Specifically, lamotrigine protected from kainate-induced seizures in wild-type mice but not in Cav2.3-null mice, where this compound in fact mediated a paradoxical increase in seizure activity that remains to be explained ${ }^{152}$. Similar observations were made with topiramate (Topamax; Mylan) ${ }^{152}$, an anticonvulsant that targets multiple types of channels and receptors, including R-type channels that are blocked in a state-dependent manner, with an $\mathrm{IC}_{50}$ (half-maximal inhibitory concentration) of around $50 \mathrm{mM}^{153}$. Although it is not clear to what extent the clinical actions of these compounds are mediated by Cav2.3 channel inhibition, the notion that Cav2.3 channels share overlapping biophysical properties with members of the Cav3 channel family fits with such a possibility. Finally, a recent study reported that Cav1.2 channels in pyramidal cells activate at relatively hyperpolarized potentials when the temperature is increased to $40^{\circ} \mathrm{C}$, thereby allowing these channels to drive intrinsic firing properties ${ }^{154}$. The authors hypothesized that this effect could contribute to the development of febrile seizures. In support of this hypothesis, nimodipine (Nimotop; Bayer) blocked the development of temperature-induced seizures in rat pups ${ }^{154}$, suggesting that dihydropyridines could be explored as a treatment option. However, nimodipine is known to weakly inhibit T-type calcium channels ${ }^{155}$, and hence it remains to be determined whether this compound inhibited febrile seizures by blocking L-type channels, T-type channels, or perhaps both.

Overall, voltage-gated calcium channels provide potential targets for both idiopathic and focal seizures, with T-type calcium channels perhaps being the most promising candidates among the calcium channel family. However, given that there are already about two dozen medications on the market that can be used to control seizures ${ }^{156}$, there has been a relative lack of new drug discovery efforts in the pharmaceutical sector.

An anti-epileptic drug with multiple cellular targets.

Nimodipine

A blocker of L-type calcium channels from the

dihydropyridine class.

Neurodegenerative disorders

Disorders caused by the loss of nerve cells during disease.

Striatum

A specific subcortical part

of the forebrain.

Tremor

Uncontrolled trembling and

shaking motion of the limbs.

Dopamine

A neurotransmitter that acts

on dopamine receptors

Isradipine

A dihydropyridine that is used

as an antihypertensive and

currently being explored as a

drug for Parkinson disease. many advances, the cellular and molecular basis of this selective neuronal loss remains to be fully understood, and this in turn has hampered the discovery of a cure for this disorder.

One possible mechanism that has been implicated in neuronal loss during Parkinson disease involves L-type Cav1.3 calcium channels. These channels can modulate pacemaking of substantia nigra neurons owing to their hyperpolarized range of voltage-dependent activation $^{163}$, although they do not appear to be critical for the pacemaking process per $\mathrm{se}^{164}$. Indeed, earlier work showing that dihydropyridines could alter the pacemaking properties of substantia nigra neurons ${ }^{165}$ may have been related to their off-target effects on other ion channels ${ }^{164}$. Nonetheless, the repetitive opening of Cav1.3 channels (and possibly also Cav1.2 channels) during pacemaking may contribute to excessive calcium entry that in turn causes cytotoxicity though mitochondrial stress ${ }^{166}$ (FIG. 4). It is also interesting to note that in human brains from patients with earlystage Parkinson disease, expression of Cav1.3 channels is increased, supporting a possible causal role of these channels in disease pathology ${ }^{167}$.

A recent study identified an additional role of Cav1.3 channels in Parkinson disease ${ }^{168}$. Calcium influx via Cav1.3 channels was shown to trigger a neuronal calcium sensor 1 (NCS1; also known as FLUP)-dependent enhancement of the activity of dopamine D2 autoreceptors (which are known to contribute to pathogenesis by virtue of their ability to regulate pacemaker activity) and loss of receptor desensitization ${ }^{168,169}$ (FIG. 4). This, in turn, would then be expected to contribute to a pathologically relevant dysregulation of dopamine neuron function. Hence, Cav1.3 channel activity may contribute to Parkinson disease pathology by multiple mechanisms, and therefore Cav1.3 channel-selective inhibitors could be a potential therapeutic strategy. Indeed, a Phase II clinical trial evaluating the safety of isradipine (Dynacirc; Reliant) as a potential Parkinson drug has been completed with promising results ${ }^{170}$. This clinical study evaluated the safety, tolerability and efficacy of isradipine in patients with early symptoms of Parkinson disease that did not yet require treatment with dopamine receptor agonists. Results showed that the drug was tolerated in a dose-dependent manner, with an optimal dose determined at $10 \mathrm{mg}$ daily. Side effects at higher doses included the development of oedema and dizziness. A large Phase III trial is currently underway at Northwestern University, Illinois, USA. It is also important to note that there is evidence that patients on dihydropyridine antihypertensives show a reduced risk of developing Parkinson disease when compared to either patients who are not on such regimens or patients who are treated with types of antihypertensives that do not cross the blood-brain barrier ${ }^{171}$.

A new class of compounds (pyrimidine-2,4,6triones) was recently identified as a possible scaffold for Cav1.3-selective inhibitors. One of the derivatives (1-(3-chlorophenethyl)-3-cyclopentylpyrimidine-2,4,6$(1 H, 3 H, 5 H)$-trione) was shown to selectively inhibit Cav1.3 channels over Cav1.2 (REF. 172). A subsequent 


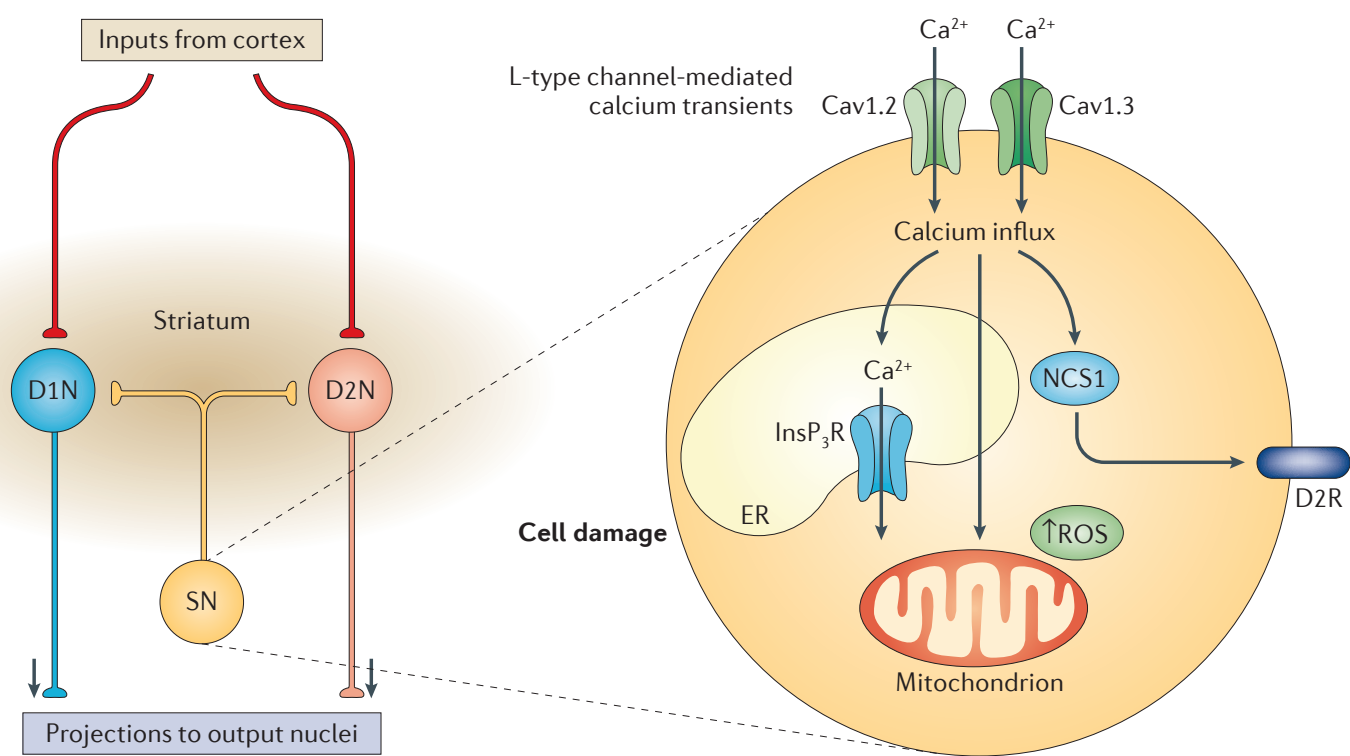

Figure 4 | Role of L-type calcium channels in the degeneration of dopaminergic neurons during Parkinson disease. Substantia nigra (SN) pars compacta neurons innervate dopamine D1 receptor-expressing neurons (D1Ns) and dopamine D2 receptor-expressing neurons (D2Ns) in the striatum, which in turn project to output nuclei. The pacemaker activity of SN neurons is modulated by Cav1.3 and possibly Cav1.2 calcium channels. The repetitive activation of Cav1.3 (and perhaps Cav1.2) channels leads to calcium influx and downstream calcium-dependent calcium release from the endoplasmic reticulum (ER). This leads to calcium elevation in the mitochondria and the generation of reactive oxygen species (ROS). This culminates in cell damage and the loss of dopaminergic neurons, and results in decreased dopaminergic input into the striatum. In addition, Cav1.3 channel activity has been linked to an increase in D2 receptor (D2R) expression via activation of neuronal calcium sensor 1 (NCS1), and this upregulation is thought to alter pacemaker activity. Ins $\mathrm{P}_{3} \mathrm{R}$, inositol-1,4,5-trisphosphate.

Ventral tegmental area A collection of specific neurons in the midbrain that is part of the reward system.

Nucleus accumbens A specific brain region that is involved in reward behaviour. study reported lower blocking affinities and weaker channel subtype selectivity of this compound compared to those reported earlier ${ }^{173}$. However, the blocking effects were also shown to vary with the $\operatorname{Cav} \beta$ subunit that was co-expressed and with the particular Cav1.3 channel splice isoform that was used ${ }^{173}$. Finally, yet another study reported that this compound in fact increased Cav1.3 channel activity by affecting channel gating in a complex manner, with inhibition only being observed when barium was used as a charge carrier ${ }^{174}$. Although the reason for these discordant observations remains unclear, one possibility may be the use of different Cav1.3 channel splice isoforms in these pharmacological tests on transiently expressed channels. Irrespective of these discrepancies in the literature, the general premise of targeting Cav1.3 channels for preventing the dopaminergic neuron loss observed in Parkinson disease remains valid.

Finally, it should be noted that T-type calcium channels have recently been implicated as a potential target for treating motor abnormalities in Parkinson disease. In a rat model, T-type calcium channel inhibitors such as mibefradil (now withdrawn from the market) and NNC-55-0396 blocked burst firing activity in slices of the subthalamic nucleus, a brain structure that is known to exhibit increased bursting activity during Parkinson disease ${ }^{175}$. Furthermore, locomotor deficits in a rat model of Parkinson disease were reduced by these compounds ${ }^{175}$. Hence, it will be interesting to determine whether new T-type channel blockers such as Z944 may show efficacy in patients with Parkinson disease.

\section{Role of calcium channels in drug dependency}

Drug dependency can be considered a chronic disease in which affected individuals experience the compelling need to consume substances of abuse, and this is a major contributor to mortality ${ }^{176,177}$. These substances include both legal drugs such as alcohol and nicotine, as well as prohibited substances such as cocaine. Dependency involves long-term changes to the brain architecture ${ }^{178}$ that predispose individuals to relapse even after very long periods of abstinence, and these may differ from brain circuits that are involved in the immediate reward associated with psychostimulants ${ }^{179,180}$. The cellular and molecular mechanisms underlying dependency are highly complex and multifaceted. The key brain structure that is involved in the development of dependency is the mesolimbic system ${ }^{181}$, in particular the dopaminergic projections from the ventral tegmental area to the nucleus accumbens and its outputs ${ }^{182}$ (FIG. 5). Even though different types of addictive substances may act at different receptors (for example, morphine activates $\mu$-opioid receptors and nicotine activates nicotinic acetylcholine receptors), they all lead to an overall increase in dopamine levels in the mesolimbic system ${ }^{183}$ and altered cAMP response element binding protein (CREB)-dependent gene expression in the ventral tegmental area and nucleus accumbens ${ }^{184}$. For over two decades, L-type channels have been known to have a role in this process ${ }^{185}$, as compounds such as nimodipine (Nimotop; Bayer) and diltiazem (Cardizem; Biovail) block behavioural sensitization to cocaine ${ }^{186,187}$ and attenuate alcohol intake ${ }^{188}$. 


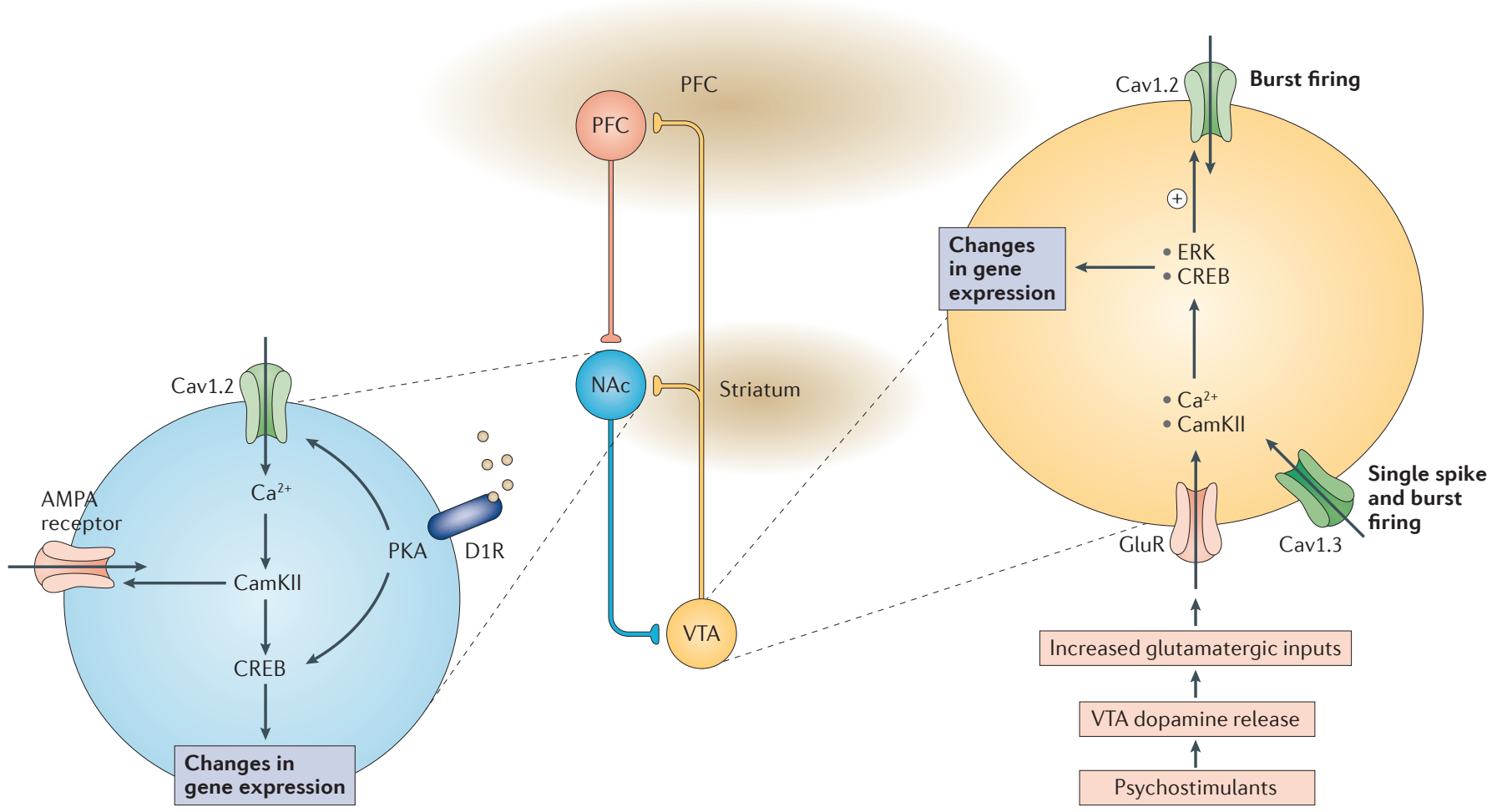

Figure 5 | Role of L-type calcium channels in drug addiction. Simplified neuronal circuitry involved in addiction is shown. Dopaminergic neurons in the ventral tegmental area (VTA) project to both the nucleus accumbens (NAc) and the prefrontal cortex (PFC). The NAc is a major output nucleus for reward-seeking behaviour and has both direct and indirect (not shown) projections back to the VTA. Chronic exposure to psychostimulants activates Cav1.3 channels and increases dopamine release from the VTA, which in turn stimulates glutamatergic inputs. Glutamate activates AMPA ( $\alpha$-amino-3hydroxy-5-methyl-4-isoxazole propionic acid) and NMDA (N-methyl-D-aspartate) receptors (GluR) on VTA neurons, and together with Cav1.3 channel activity it leads to changes in gene expression that include the upregulation of Cav1.2 calcium channels. Cav1.2 and Cav1.3 channels differentially regulate the firing behaviour of VTA neurons, which in turn drives dopamine release in the NAc. There, activation of dopamine D1 receptors (D1Rs) activates protein kinase A (PKA), which, together with an upregulation of Cav1.2 channels, mediates long-term changes in gene expression and AMPA receptor insertion into the plasma membrane. CamKII, calcium/calmodulin-dependent protein kinase II; CREB, cAMP response element binding protein; ERK, extracellular signal-regulated kinase; GluR, glutamate receptor.

The Cav1.3 calcium channel subtype appears to contribute to the amphetamine-induced upregulation of dopamine receptor mRNA in the ventral tegmental area ${ }^{189}$ and is essential for behavioural sensitization in response to cocaine and amphetamines ${ }^{190}$. After pre-exposure to cocaine, Cav1.2 channels are upregulated in the nucleus accumbens, which in turn causes long-term changes in gene expression and a phosphorylation-dependent insertion of AMPA ( $\alpha$-amino-3hydroxy-5-methyl-4-isoxazole propionic acid) receptors into the plasma membrane, which gives rise to longterm plasticity ${ }^{190,191}$ (FIG. 5). This process depends on the activation of Cav1.3 channels in the ventral tegmental area $^{192}$, presumably via the release of dopamine and activation of D1 receptors. This plasticity is maintained after cocaine withdrawal. Conversely, in the dorsal striatum, long-term cocaine exposure causes a decrease in AMPA receptor phosphorylation or insertion that depends on the activation of D2 receptors and Cav1.3 channels, but not on those that are expressed in the ventral tegmental area ${ }^{191}$. Furthermore, during chronic methamphetamine treatment, there is an increase in Cav1.2
mRNA expression in ventral tegmental area neurons, which may also contribute to long-term changes in gene expression ${ }^{189,193}$. A subsequent study revealed that Cav1.2 and Cav1.3 channels mediate distinct neuronal firing patterns in ventral tegmental area neurons, with Cav1.3 channels driving both single spike and burst firing, whereas Cav1.2 channels are mainly important for bursting behaviour ${ }^{194}$ (FIG. 5). This, in turn, suggests that these two channel types differentially contribute to dopaminergic modulation of the nucleus accumbens.

Altogether, a picture emerges in which Cav1.3 channels are crucial mediators of plastic changes in the mesolimbic system in response to psychostimulants, which then lead to a longer form of plasticity in the nucleus accumbens that is dependent on the Cav1.2 channel. The latter may perhaps contribute to the long-term structural changes that predispose individuals to relapse after abstinence. This therefore suggests that L-type calcium channel blockers could prove beneficial in the treatment of addiction. Indeed, there is evidence from human studies that this may be the case $\mathrm{e}^{195,196}$. For example, L-type calcium channel inhibitors such as nifedipine (Procardia/Adalat; Pfizer/Bayer) 
and verapamil (Calan; Pfizer) have been shown to reduce withdrawal symptoms from a number of addictive substances, including opiates and ethanol ${ }^{195,196}$. It remains to be determined whether these effects in humans are dependent on the activity of Cav1.3, Cav1.2, or both types of channels. Such knowledge could potentially guide future therapeutic strategies in this setting.

In addition to L-type calcium channels, blockers of other types of calcium channels may also be a useful strategy. A mixed N-type/T-type calcium channel blocker (NMED-126; also known as NP078585) was shown to reduce alcohol intoxication in mice, as well as alcohol self-administration and reinstatement ${ }^{197}$. The effects of this compound were absent in Cav2.2-knockout mice, indicating that it acted predominantly via $\mathrm{N}$-type rather than T-type channel inhibition. Whether these effects occur at the network level in the mesolimbic system is not known; nonetheless, these data point to a potential strategy of using mixed $\mathrm{N}$-type/L-type channel inhibitors to target drug and alcohol dependency. One such blocker that is used currently in the clinic is cilnidipine (Atelec/ Cilacar; Fuji/Ajinomoto), an antihypertensive from the dihydropyridine class $^{70}$. Importantly, this compound suppresses ethanol-induced locomotor sensitization in rats ${ }^{198}$.

\section{Calcium channels and psychiatric disorders}

Several calcium channel genes have been associated with the development of psychiatric symptoms. Singlenucleotide polymorphisms in intron sequences in the gene encoding Cav1.2 (in particular, a risk locus termed rs1006737) and in the Cav $\beta 2$ subunit have been associated with an increased risk of bipolar disorder and schizophrenia ${ }^{199,200}$. Importantly, healthy individuals carrying the CACNA1C rs 1006737 risk variant show compromised function of the anterior cingulate cortex, prefrontal cortex and hippocampus in functional magnetic resonance imaging (MRI) studies ${ }^{201-203}$. A subsequent study identified Cav1.3 as another possible risk gene for bipolar disorder, with a lower degree of association for Cav2.2 and Cav3.1 (REF. 204). It was concluded that these channels and other types of ionic channels share a common role in regulating neuronal excitability; however, this may be an overly simplistic view as these channels have highly specialized roles that can differ across brain regions ${ }^{7}$. How polymorphisms in intronic sequences of Cav1.2 may contribute to an increased risk of schizophrenia is not yet understood. It is possible that they could lead to altered expression of Cav1.2 channels ${ }^{205}$, and this would be consistent with a recent report showing higher Cav1.2 activity in induced neurons from carriers of the polymorphism ${ }^{206}$. Nonetheless, the association of bipolar disorders with two different types of L-type calcium channels suggests that L-type calcium channel blockers are a possible treatment avenue. Indeed, a preliminary clinical study on the use of isradipine for the treatment of bipolar disorder yielded promising results ${ }^{207}$, but this needs to be followed up with larger cohort studies.

Gain-of-function mutations in Cav1.2 that interfere with the normal voltage-dependent inactivation mechanisms in these channels have been associated with Timothy syndrome, a severe condition that includes fatal cardiac arrhythmias, developmental abnormalities and autism ${ }^{208,209}$. This change in channel function not only affects the electrophysiological properties of excitable cells but, as evident from studies on neuronal progenitor cells from patients with Timothy syndrome, also leads to massive alterations in gene transcription ${ }^{210}$ and enhanced dendritic retraction ${ }^{211}$. An autistic phenotype is also observed in human patients with gain-offunction mutations in Cav1.3 channels ${ }^{212}$. Furthermore, rare mutations in the $\operatorname{Cav} \beta 2$ subunit in families with autism spectrum disorder lead to slowed L-type calcium channel inactivation kinetics ${ }^{213}$. This raises the possibility that L-type calcium channel inhibitors or, more specifically, L-type channel inactivation enhancers, could be used as treatments for certain types of autism. However, so far there have been no clinical trials to test this hypothesis. It is also noteworthy that single-nucleotide polymorphisms in all three Cav3 channel isoforms have been associated with autism ${ }^{214}$. In the case of Cav3.2, such mutations have been shown to cause a loss of function $^{215}$. To what extent Cav3 channels can be exploited as potential targets for autism remains to be determined.

Anxiety disorders are another group of highly prevalent psychiatric conditions that may involve voltage-gated calcium channels. Anxiety can be defined as an apprehensive reaction to a non-threatening stimulus, and it is thus not surprising that the neural circuitry that is involved in anxiety is intimately tied to that of fear ${ }^{216,217}$, which encompasses the amygdala, the nucleus accumbens and the hippocampus ${ }^{218}$. Optogenetics-based studies have revealed that inputs from the amygdala to the hippocampus are essential for the development of anxiety-related behaviours ${ }^{219}$. A recent study reported an increase in the expression of the Cava $2 \delta 1$ subunit in the amygdala in a rat model of chemically induced anxiety ${ }^{220}$. Notably, pregabalin reversed the anxiety phenotype, which fits with ample clinical data showing that both gabapentin and pregabalin are effective in treating anxiety disorders in humans ${ }^{221}$. The upregulation of Cava $\delta$ subunits appears to be accompanied by an increase in the expression of Cav1.2 and Cav1.3 calcium channels ${ }^{222}$. Along these lines, there is an increase in the expression of Cav1.2 calcium channels in fear-conditioned rats ${ }^{222}$. In these experiments, nimodipine was shown to block startle responses ${ }^{222}$. Although these findings raise the possibility of testing L-type calcium channel inhibitors as potential anxiolytics, deletion of Cav1.2 channels in the forebrain appears to give rise to an anxiety phenotype in mice ${ }^{223}$, as does haploinsufficiency of Cav1.2 channels in female mice ${ }^{224}$. Moreover, higher doses of nifedipine and verapamil have been shown to exert anxiogenic effects in mice ${ }^{225}$. Conversely, there are weak indications that Cav1.3 deficiency may have anxiolytic effects ${ }^{226}$. Therefore, it is currently unclear whether L-type channels may serve as targets for anxiety disorders and how they modulate the underlying neuronal circuitry.

It is important to note that $\mathrm{N}$-type channels may also have a role in the development of anxiety disorders, as mice lacking Cav2.2 display reduced levels of anxiety ${ }^{227}$. It is conceivable that the aforementioned anxiolytic effects of gabapentin could be due to a Cav $\alpha 2 \delta$-dependent effect 
on Cav2.2 channels ${ }^{228}$. Finally, mice lacking the Cav $\beta 3$ subunit show reduced anxiety along with increased aggression $^{229}$, and it is possible that this is due to reduced expression of Cav2.2 channels arising from the absence of this important auxiliary subunit.

Overall, there is evidence supporting the utility of voltage-gated calcium channel blockers in a variety of psychiatric disorders. What remains to be understood in greater depth is how individual calcium channel isoforms contribute to the development of such conditions at the neuronal network level.

\section{Challenges and opportunities}

The importance of voltage-gated calcium channels as drug targets for nervous system disorders has been clearly established. As there are already clinically approved inhibitors of $\mathrm{N}$-, L- and T-type calcium channels, this may allow the rapid testing of these existing drugs in a wide range of neurological conditions, as exemplified by the use of the antihypertensive isradipine as a potential intervention for Parkinson disease ${ }^{170}$. Furthermore, as calcium channels have important roles in many other physiological processes, such as the regulation of sleep patterns ${ }^{138,230}$ and food intake $e^{231}$, the palette of possible therapeutic applications of calcium channel inhibitors may well increase to include conditions such as insomnia and eating disorders, among others. Nonetheless, there remains a pressing need for new calcium channel blockers, especially for conditions such as neuropathic and inflammatory pain, which are often refractory to treatment. In particular, to minimize side effects, it is important to develop new types of calcium channel inhibitors that specifically target the calcium channels that are involved in pathophysiological processes, while sparing those that contribute to normal physiological function. This requires an in-depth understanding of how calcium channels partake in the function of specific brain circuits that are implicated in pathophysiology and how these channels may be dysregulated in pathological states.

First, it is important to know the precise molecular architecture of the channels expressed in these neurons, which, as noted earlier in this article, may guide drug discovery strategies. For example, it has been shown that Cav2.2 calcium channels in pain-sensing neurons contain exon 37 a rather than exon $37 \mathrm{~b}$, which is more widely expressed in the nervous system ${ }^{232}$ and that the exon37a variant is critical for pain signalling ${ }^{233}$. If one were to develop an inhibitor that selectively targets exon37acontaining channels, then the potential of CNS side effects may be reduced. Along these lines, it is possible that calcium channels undergo age-dependent alternative splicing events (this has been demonstrated at least for P/Q-type channels) ${ }^{234}$, and this could potentially be relevant for the pathogenic role of Cav1.3 calcium channels in Parkinson disease. In the context of ageing, matters are further complicated by the fact that Cav1.2 channels undergo an age-dependent form of proteolysis in the plasma membrane that results in the generation of functional channels with altered biophysical characteristics ${ }^{235}$. Besides modification of the pore-forming channel subunit per se, knowledge of the association of the calcium channel Caval subunits with specific ancillary subunits and the interactions of calcium channels with other regulatory elements, may be important considerations for drug development. For example, Cav1.3 channels in cochlear hair cells associate with calcium-binding proteins such as $\mathrm{CaBP} 2$ and $\mathrm{CaBP} 4$, which changes the biophysical and perhaps the pharmacological characteristics of these channels ${ }^{236,237}$. When designing Cav1.3 channel inhibitors for the treatment of conditions such as Parkinson disease or addiction, it may thus prove advantageous to select compounds with lower affinity for channels that are complexed with CaBP2, in order to avoid the possibility of drug-induced hearing deficiencies. This could be accomplished by screening compounds against cell lines that stably co-express CaBP2 and Cav1.3 channels.

Second, it is important to understand the intrinsic firing properties of the neuronal circuits that are involved in pathological states. For example, hyperexcitability disorders such as epilepsy may call for calcium channel blockers that are strongly use-dependent. This strategy has been successfully exploited with anti-arrhythmic and anticonvulsant drugs and, as noted above, it is possible to identify these types of compounds with new drug screening technologies ${ }^{238}$. Indeed, several of the newer T-type calcium channel blockers such as Z944 exhibit this feature, as does the N-type channel inhibitor TROX-1. In other cases, it may prove advantageous to develop tonic blockers of a particular calcium channel subtype.

Third, it may be possible to target aberrant upregulation of calcium channels, as seen in pain-sensing neurons after injury. Indeed, such an approach has been demonstrated for the interactions between Cav2.2 channels and collapsin response mediator protein 2 (CRMP2; also known as DRP2), which promotes stability of the channel complex in the plasma membrane ${ }^{239}$. Uncoupling of CRMP2 from the channel via disruptor peptides reduces calcium currents and mediates analgesia ${ }^{239}$. Along these lines, interactions between Cav3.2 calcium channels and the deubiquitinase ubiquitin-specific processing protease 5 (USP5) have been shown to promote enhanced channel expression in the plasma membrane in a range of chronic pain conditions ${ }^{240}$. Disruptor peptides that interfered with the association of the two proteins prevented this aberrant upregulation, thereby mediating analgesia. Importantly, small organic mimetics of these peptides that were identified in an enzyme-linked immunosorbent assay (ELISA) screen prevented the USP5-Cav3.2 interaction in vitro and blocked the development of pain hypersensitivity in several different animal models ${ }^{241}$. This is an example in which targeting a protein-protein interaction can be exploited towards therapeutic indications. Because such protein-protein interactions often occur in intracellular regions in which there is greater sequence divergence among various calcium channel isoforms, this approach has the potential to achieve greater target selectivity. Furthermore, by targeting an association that occurs in a pathophysiological state and not under normal physiological conditions, the potential of interfering with normal physiology (and thus the possibility of side effects) is minimized. 
Channelopathies

A group of conditions in which mutations in specific ion

channels give rise to disease.
Finally, knowledge of how mutations in calcium channel genes alter channel function can be exploited towards the development of therapeutics. This is exemplified by a recent study in which a gain-of-function mutation in Cav2.1 causing familial hemiplegic migraine was introduced into Drosophila melanogaster and shown to alter synaptic physiology at the neuromuscular junction $^{242}$. A compound (ter-butyl dihydroquinone) that is able to offset the enhancement of channel function to normalize the synaptic defects associated with the mutation was then applied, thus restoring normal synaptic physiology. Although such a targeted approach has not been described for treating calcium channelopathies in humans, it has been successfully applied to patients with erythromelalgia who have gain-of-function mutations in Nav1.7 sodium channels ${ }^{243}$. It may thus be possible to adopt similar strategies for gain-of-function calcium channelopathies such as absence epilepsy, migraine or Timothy syndrome.

Altogether, there remains tremendous untapped potential towards the design of new calcium channel blockers for the precise (and perhaps personalized) targeting of a wide range of neurophysiological and psychiatric conditions. The above considerations underscore the need for fundamental insights into the roles of calcium channels in nervous system function at the cellular, molecular and network level. With many of the large pharmaceutical companies reducing in-house discovery efforts, this important task may need to fall on the academic community.
1. Cain, S. M. \& Snutch, T. P. T-type calcium channels in burst-firing, network synchrony, and epilepsy. Biochim. Biophys. Acta 1828, 1572-1578 (2013).

2. Hook, S. S. \& Means, A. R. $\mathrm{Ca}^{2+} / \mathrm{CaM}$-dependent kinases: from activation to function. Annu. Rev. Pharmacol. Toxicol. 41, 471-505 (2001).

3. Wheeler, D. B., Randall, A. \& Tsien, R. W. Roles of $\mathrm{N}$-type and $\mathrm{Q}$-type $\mathrm{Ca}^{2+}$ channels in supporting hippocampal synaptic transmission. Science 264, 107-111 (1994).

4. Dolmetsch, R. E., Pajvani, U., Fife, K., Spotts, J. M. \& Greenberg, M. E. Signaling to the nucleus by an L-type calcium channel-calmodulin complex through the MAP kinase pathway. Science 294, 333-339 (2001).

5. Wheeler, D. G. et al. $\mathrm{Ca}_{\mathrm{v}} 1$ and $\mathrm{Ca}_{\mathrm{v}} 2$ channels engage distinct modes of $\mathrm{Ca}^{2+}$ signaling to control CREBdependent gene expression. Cell 149, 1112-1124 (2012).

6. Tanabe, T., Beam, K. G., Adams, B. A., Niidome, T. $\&$ Numa, S. Regions of the skeletal muscle dihydropyridine receptor critical for excitation-contraction coupling. Nature 346, 567-569 (1990).

7. Simms, B. A. \& Zamponi, G. W. Neuronal voltagegated calcium channels: structure, function, and dysfunction. Neuron 82, 24-45 (2014).

8. Catterall, W. A., Perez-Reyes, E., Snutch, T. P. \& Striessnig, J. International union of pharmacology. XLVIII. Nomenclature and structure-function relationships of voltage-gated calcium channels. Pharmacol. Rev. 57, 411-425 (2005).

9. Lipscombe, D., Andrade, A. \& Allen, S. E. Alternative splicing: functional diversity among voltage-gated calcium channels and behavioral consequences. Biochim. Biophys. Acta 1828, 1522-1529 (2013).

10. Dolphin, A. C. Calcium channel auxiliary $\alpha_{2} \delta$ and $\beta$ subunits: trafficking and one step beyond. Nat. Rev. Neurosci. 13, 542-555 (2012).

11. Lory, P. \& Mezghrani, A. Calcium channelopathies in inherited neurological disorders: relevance to drug screening for acquired channel disorders. IDrugs 13, 467-471 (2010)

12. Felix, R. Calcium channelopathies. Neuromolecular Med. 8, 307-318 (2006)

13. Bean, B. P. Classes of calcium channels in vertebrate cells. Annu. Rev. Physiol. 51, 367-384 (1989).

14. Nowycky, M. C., Fox, A. P. \& Tsien, R. W. Three types of neuronal calcium channel with different calcium agonist sensitivity. Nature 316, 440-443 (1985).

15. Perez-Reyes, E. Molecular physiology of low-voltageactivated t-type calcium channels. Physiol. Rev. 83, 117-161 (2003).

16. Bourinet, E. et al. Splicing of $\alpha_{1 \mathrm{~A}}$ subunit gene generates phenotypic variants of P-and Q-typ calcium channels. Nat. Neurosci. 2, 407-415 (1999).

17. Richards, K. S., Swensen, A. M., Lipscombe, D. \& Bommert, K. Novel $\mathrm{Ca}_{\mathrm{v}} 2.1$ clone replicates many properties of Purkinje cell $\mathrm{Ca}_{\mathrm{v}} 2.1$ current. Eur. J. Neurosci. 26, 2950-2961 (2007).

18. Catterall, W. A. Ion channel voltage sensors: structure, function, and pathophysiology. Neuron 67, 915-928 (2010).
19. Bladen, C. \& Zamponi, G. W. Common mechanisms of drug interactions with sodium and T-type calcium channels. Mol. Pharmacol. 82, 481-487 (2012).

20. Sinnegger, M. J. et al. Nine L-type amino acid residues confer full 1,4-dihydropyridine sensitivity to the neuronal calcium channel $\alpha_{14}$ subunit. Role of L-type Met $^{1188}$. J. Biol. Chem. 272, 27686-27693 (1997).

21. Striessnig, J. et al. Structural basis of drug binding to $\mathrm{L} \mathrm{Ca}^{2+}$ channels. Trends Pharmacol. Sci. 19, 108-115 (1998).

22. Catterall, W. A. Voltage-gated calcium channels. Cold Spring Harb. Perspect. Biol. 3, a003947 (2011).

23. Pragnell, $M$. et al. Calcium channel $\beta$-subunit binds to a conserved motif in the I-II cytoplasmic linker of the $\alpha 1$-subunit. Nature 368, 67-70 (1994).

24. Dolphin, A. C. The $\alpha_{2} \delta$ subunits of voltage-gated calcium channels. Biochim. Biophys. Acta 1828 1541-1549 (2012)

25. Altier, C. et al. The Cav $\beta$ subunit prevents RFP2-mediated ubiquitination and proteasomal degradation of L-type channels. Nat. Neurosci. 14, 173-180 (2011).

This paper shows that ancillary $\operatorname{Cav} \beta$ subunits regulate calcium channel trafficking by interfering with the ubiquitylation of the channels.

26. Tran-Van-Minh, A. \& Dolphin, A. C. The $\alpha 2 \delta$ ligand gabapentin inhibits the Rab11-dependent recycling of the calcium channel subunit $\alpha 2 \delta$-2. J. Neurosci. 30 12856-12867 (2010)

27. Kang, M. G. \& Campbell, K. P. Gamma subunit of voltage-activated calcium channels. J. Biol. Chem. 278, 21315-21318 (2003).

28. Lipscombe, D., Andrade, A. \& Allen, S. E. Alternative splicing: functional diversity among voltage-gated calcium channels and behavioral consequences. Biochim. Biophys. Acta 1828, 1522-1529 (2012).

29. Sinnegger-Brauns, M. J. et al. Expression and 1,4-dihydropyridine-binding properties of brain L-type calcium channel isoforms. Mol. Pharmacol. 75, 407-414 (2009).

30. Hell, J. W. et al. Identification and differential subcellular localization of the neuronal class $C$ and class D L-type calcium channel $\alpha 1$ subunits. J. Cell Biol. 123, 949-962 (1993).

31. Hutchinson, T. E., Zhong, W., Chebolu, S. Wilson, S. M. \& Darmani, N. A. L-type calcium channels contribute to $5-\mathrm{HT}_{3}$-receptor-evoked CaMKIl $\alpha$ and ERK activation and induction of emesis in the least shrew (Cryptotis parva). Eur. J. Pharmacol. 755, 110-118 (2015).

32. Ramirez-Latorre, J. A. Functional upregulation of $\mathrm{Ca}^{2+}$-activated $\mathrm{K}^{+}$channels in the development of substantia nigra dopamine neurons. PLOS ONE 7, e51610 (2012)

33. Brandt, A., Khimich, D. \& Moser, T. Few $\mathrm{Ca}_{v} 1.3$ channels regulate the exocytosis of a synaptic vesicle at the hair cell ribbon synapse. J. Neurosci. 25 11577-11585 (2005)

34. Platzer, J. et al. Congenital deafness and sinoatrial node dysfunction in mice lacking class D L-type $\mathrm{Ca}^{2+}$ channels. Cell 102, 89-97 (2000).

This elegant paper implicates Cav1.3 channels in both cardiovascular function and the detection of auditory stimuli.
35. Baig, S. M. et al. Loss of $\mathrm{Ca}_{\mathrm{v}} 1.3$ (CACNA1D) function in a human channelopathy with bradycardia and congenital deafness. Nat. Neurosci. 14, 77-84 (2011).

36. Lodha, N. et al. Congenital stationary night blindness in mice - a tale of two Cacna If mutants. Adv. Exp. Med. Biol. 664, 549-558 (2010).

37. Lodha, N., Loucks, C. M., Beaulieu, C. Parboosingh, J. S. \& Bech-Hansen, N. T. Congenital stationary night blindness: mutation update and clinical variability. Adv. Exp. Med. Biol. 723, 371-379 (2012).

38. Zamponi, G. W. Regulation of presynaptic calcium channels by synaptic proteins. J. Pharmacol. Sci. 92, 79-83 (2003)

39. Cao, Y. Q. et al. Presynaptic $\mathrm{Ca}^{2+}$ channels compete for channel type-preferring slots in altered neurotransmission arising from $\mathrm{Ca}^{2+}$ channelopathy. Neuron 43, 387-400 (2004).

40. Hatakeyama, S. et al. Differential nociceptive responses in mice lacking the $\alpha_{1 \mathrm{~B}}$ subunit of $\mathrm{N}$-type $\mathrm{Ca}^{2+}$ channels. Neuroreport 12, 2423-2427 (2001).

41. Jun, K. et al. Ablation of $\mathrm{P} / \mathrm{Q}$-type $\mathrm{Ca}^{2+}$ channel currents, altered synaptic transmission, and progressive ataxia in mice lacking the alpha ${ }_{1 A}$-subunit. Proc. Natl Acad. Sci. USA 96, 15245-15250 (1999).

42. Sutton, K. G., McRory, J. E., Guthrie, H., Murphy, T. H. $\&$ Snutch, T. P. P/Q-type calcium channels mediate the activity-dependent feedback of syntaxin-1A. Nature 401, 800-804 (1999).

43. Vecchia, D., Tottene, A., van den Maagdenberg, A. M. \& Pietrobon, D. Abnormal cortical synaptic transmission in $\mathrm{Ca}_{v} 2.1$ knockin mice with the $\mathrm{S} 218 \mathrm{~L}$ missense mutation which causes a severe familial hemiplegic migraine syndrome in humans. Front. Cell Neurosci. 9, 8 (2015)

44. Nachbauer, W. et al. Episodic ataxia type 2: phenotype characteristics of a novel CACNA1A mutation and review of the literature. J. Neurol. 261, 983-991 (2014).

45. Saegusa, H. et al. Properties of human $\mathrm{Ca}_{v} 2.1$ channel with a spinocerebellar ataxia type 6 mutation expressed in Purkinje cells. Mol. Cell Neurosci. 34, 261-270 (2007).

46. Groen, J. L. et al. CACNA1B mutation is linked to unique myoclonus-dystonia syndrome. Hum. Mol. Genet. 24, 987-993 (2015)

47. Wu, L. G., Borst, J. G. \& Sakmann, B. R-type Ca ${ }^{2+}$ currents evoke transmitter release at a rat central synapse. Proc. Natl Acad. Sci. USA 95, 4720-4725 (1998).

48. Ricoy, U. M. \& Frerking, M. E. Distinct roles for Ca 2.1-2.3 in activity-dependent synaptic dynamics. J. Neurophysiol. 111, 2404-2413 (2014).

49. Zaman, T. et al. Ca 2.3 channels are critical for oscillatory burst discharges in the reticular thalamus and absence epilepsy. Neuron 70, 95-108 (2011).

50. Coulter, D. A., Huguenard, J. R. \& Prince, D. A Calcium currents in rat thalamocortical relay neurones: kinetic properties of the transient, lowthreshold current. J. Physiol. 414, 587-604 (1989).

51. Molineux, M. L. et al. Specific T-type calcium channel isoforms are associated with distinct burst phenotypes in deep cerebellar nuclear neurons. Proc. Natl Acad. Sci. USA 103, 5555-5560 (2006). 
52. Chemin, J., Monteil, A., Bourinet, E., Nargeot, J \& Lory, P. Alternatively spliced $\alpha_{1 \mathrm{C}}\left(\mathrm{Ca}_{\mathrm{v}}\right.$ 3.1) intracellular loops promote specific T-type $\mathrm{Ca}^{2+}$ channel gating properties. Biophys. J. 80, 1238-1250 (2001).

53. Weiss, N. et al. A Ca 3.2/syntaxin-1 A signaling complex controls T-type channel activity and lowthreshold exocytosis. J. Biol. Chem. 287, 2810-2818 (2012).

54. Fleckenstein, A., Kammermeier, H., Doring, H. J. \& Freund, H. J. [On the method of action of new types of coronary dilatators with simultaneous oxygen-saving myocardial effects, prenylamine and iproveratril. 2]. Z. Kreislaufforsch. 56, 839-858 (1967).

55. Doering, C. J. \& Zamponi, G. W. Molecular pharmacology of high voltage-activated calcium channels. J. Bioenerg. Biomembr. 35, 491-505 (2003).

56. Glossmann, H., Ferry, D. R., Lubbecke, F., Mewes, R. $\S$ Hofmann, F. Identification of voltage operated calcium channels by binding studies: differentiation of subclasses of calcium antagonist drugs with $3 \mathrm{H}$-nimodipine radioligand binding. J. Recept. Res. 3, 177-190 (1983).

57. Glossmann, H., Ferry, D. R., Goll, A. \& Rombusch, M. Molecular pharmacology of the calcium channel: evidence for subtypes, multiple drug-receptor sites, channel subunits, and the development of a radioiodinated 1,4-dihydropyridine calcium channe label, [1 25I]iodipine. J. Cardiovasc. Pharmacol. 6 (Suppl. 4), 608-621 (1984).

58. Benjamin, E. R. et al. Pharmacological characterization of recombinant $\mathrm{N}$-type calcium channel ( $\left.\mathrm{Ca}_{\mathrm{v}} 2.2\right)$ mediated calcium mobilization using FLIPR. Biochem. Pharmacol. 72, 770-782 (2006).

59. Xie, X. et al. Validation of high throughput screening assays against three subtypes of $\mathrm{Ca}_{\mathrm{v}} 3 \mathrm{~T}$-type channels using molecular and pharmacologic approaches. Assay Drug Dev. Technol. 5, 191-203 (2007).

60. Vetter, I. Development and optimization of FLIPR high throughput calcium assays for ion channels and GPCRs. Adv. Exp. Med. Biol. 740, 45-82 (2012)

61. Tao, H. et al. Efficient characterization of use dependent ion channel blockers by real-time monitoring of channel state. Assay Drug Dev. Technol. 4, 57-64 (2006)

62. Dai, G. et al. A high-throughput assay for evaluating state dependence and subtype selectivity of $\mathrm{Ca}_{v} 2$ calcium channel inhibitors. Assay Drug Dev. Technol. 6. 195-212 (2008)

63. Belardetti, F. et al. A fluorescence-based highthroughput screening assay for the identification of T-type calcium channel blockers. Assay Drug Dev. Technol. 7, 266-280 (2009).

64. Balasubramanian, B et al Optimization of $\mathrm{Ca}_{\mathrm{v}} 1.2$ screening with an automated planar patch clamp platform. J. Pharmacol. Toxicol. Methods 59 62-72 (2009)

65. Kraus, R. et al. Identification of benz(othi)azepinebinding regions within L-type calcium channel $\alpha 1$ subunits. J. Biol. Chem. 271, 20113-20118 (1996).

66. Stotz, S. C., Jarvis, S. E. \& Zamponi, G. W. Functional roles of cytoplasmic loops and pore lining transmembrane helices in the voltage-dependent inactivation of HVA calcium channels. J. Physiol. 554, 263-273 (2004)

67. Zamponi, G. W. et al. Unique structure-activity relationship for 4-isoxazolyl-1,4-dihydropyridines. J. Med. Chem. 46, 87-96 (2003).

68 Catterall, W. A. \& Swanson, T. M. Structural basis for pharmacology of voltage-gated sodium and calcium channels. Mol. Pharmacol. 88, 141-150 (2015).

69. Bladen, C., Gunduz, M. G., Simsek, R., Safak, C. \& Zamponi, G. W. Synthesis and evaluation of 1,4-dihydropyridine derivatives with calcium channel blocking activity. Pflugers Arch. 466, 1355-1363 (2014).

70. Fujii, S., Kameyama, K., Hosono, M., Hayashi, Y. $\&$ Kitamura, K. Effect of cilnidipine, a novel dihydropyridine $\mathrm{Ca}^{++}$-channel antagonist, on $\mathrm{N}$-type $\mathrm{Ca}^{++}$channel in rat dorsal root ganglion neurons. J. Pharmacol. Exp. Ther. 280, 1184-1191 (1997)

71. Kumar, P. P. et al. Synthesis and evaluation of a new class of nifedipine analogs with T-type calcium channe blocking activity. Mol. Pharmacol. 61, 649-658 (2002).

72. Basbaum, A. I., Bautista, D. M., Scherrer, G. \& Julius, D. Cellular and molecular mechanisms of pain. Cell 139, 267-284 (2009).

73. Bourinet, E. et al. Calcium-permeable ion channels in pain signaling. Physiol. Rev. 94, 81-140 (2014).
74. Waxman, S. G. \& Zamponi, G. W. Regulating excitability of peripheral afferents: emerging ion channel targets. Nat. Neurosci. 17, 153-163 (2014)

75. Cizkova, D. et al. Localization of $\mathrm{N}$-type $\mathrm{Ca}^{2+}$ channels in the rat spinal cord following chronic constrictive nerve injury. Exp. Brain Res. 147, 456-463 (2002)

76. Marger, F. et al. T-type calcium channels contribute to colonic hypersensitivity in a rat model of irritable bowel syndrome. Proc. Natl Acad. Sci. USA 108, 11268-11273 (2011)

This paper elegantly demonstrates that irritable bowel syndrome causes an upregulation of Cav3.2 channels in DRG neurons that innervate the colon.

77. Jagodic, M. M. et al. Upregulation of the T-type calcium current in small rat sensory neurons after chronic constrictive injury of the sciatic nerve. J. Neurophysiol. 99, 3151-3156 (2008)

78. Tedford, H. W. \& Zamponi, G. W. Direct G protein modulation of $\mathrm{Ca}_{2} 2$ calcium channels. Pharmacol. Rev. 58, 837-862 (2006).

79. Jiang, Y. Q., Andrade, A. \& Lipscombe, D. Spinal morphine but not ziconotide or gabapentin analgesia is affected by alternative splicing of voltage-gated calcium channel $\mathrm{Ca}_{v} 2.2$ pre-mRNA. Mol. Pain 9, 67 (2013)

80. Kuo, A., Wyse, B. D., Meutermans, W. \& Smith, M. T. In vivo profiling of seven common opioids for antinociception, constipation and respiratory depression: no two opioids have the same profile. Br. J. Pharmacol. 172, 532-548 (2015).

81. Luo, Z. D. et al. Upregulation of dorsal root ganglion $\alpha_{2} \delta$ calcium channel subunit and its correlation with allodynia in spinal nerve-injured rats. J. Neurosci. 21, 1868-1875 (2001).

82. Bauer, C. S. et al. The increased trafficking of the calcium channel subunit $\alpha_{2} \delta-1$ to presynaptic terminals in neuropathic pain is inhibited by the $\alpha_{2} \delta$ ligand pregabalin. J. Neurosci. 29, 4076-4088 (2009)

This paper shows that gabapentinoids prevent synaptic targeting of calcium channels.

83. Bauer, C. S. et al. The anti-allodynic $\alpha_{2} \delta$ ligand pregabalin inhibits the trafficking of the calcium channel $\alpha_{2} \delta$-1 subunit to presynaptic terminals in vivo. Biochem. Soc. Trans. 38, 525-528 (2010).

84. Hendrich, J., Bauer, C. S. \& Dolphin, A. C Chronic pregabalin inhibits synaptic transmission between rat dorsal root ganglion and dorsal horn neurons in culture. Channels 6, 124-132 (2012).

85. Johnson, R. W. \& Rice, A. S. Clinical practice. Postherpetic neuralgia. N. Engl. J. Med. 371 1526-1533 (2014)

86. Miljanich, G. P. Ziconotide: neuronal calcium channe blocker for treating severe chronic pain. Curr. Med. Chem. 11, 3029-3040 (2004).

87. Rauck, R. L., Wallace, M. S., Burton, A. W., Kapural, L. \& North, J. M. Intrathecal ziconotide for neuropathic pain: a review. Pain Pract. 9, 327-337 (2009).

88. Staats, P. S. et al. Intrathecal ziconotide in the treatment of refractory pain in patients with cance or AIDS: a randomized controlled trial. JAMA 291 63-70 (2004)

This important paper validates the use of $\mathrm{N}$-type calcium channel blockers as a therapeutic strategy for treating pain in humans.

89. Smith, H. S. \& Deer, T. R. Safety and efficacy of intrathecal ziconotide in the management of severe chronic pain. Ther Clin. Risk Manag 5, 521-534 (2009).

90. Rauck, R. L. et al. A randomized, double-blind, placebo-controlled study of intrathecal ziconotide in adults with severe chronic pain. J. Pain Symptom Manage. 31, 393-406 (2006).

91 Wallace, M. S. et al. Intrathecal ziconotide in the treatment of chronic nonmalignant pain a randomized, double-blind, placebo-controlled clinical trial. Neuromodulation 9, 75-86 (2006).

92. Feng Z. P et al. Determinants of inhibition of transiently expressed voltage-gated calcium channels by $\omega$-conotoxins GVIA and MVIIA. J. Biol. Chem. 278 20171-20178 (2003)

93. Zamponi, G. W. et al. Scaffold-based design and synthesis of potent $\mathrm{N}$-type calcium channel blockers. Bioorg. Med. Chem. Lett. 19, 6467-6472 (2009)

94. Swensen, A. M. et al. Characterization of the substituted N-triazole oxindole TROX-1, a smallmolecule, state-dependent inhibitor of $\mathrm{Ca}_{\mathrm{V}} 2$ calcium channels. Mol. Pharmacol. 81, 488-497 (2012).
95 Ryder, T R et al Multiple parallel synthesis of $\mathrm{N}, \mathrm{N}$-dialkyldipeptidylamines as $\mathrm{N}$-type calcium channel blockers. Bioorg. Med. Chem. Lett. 9, 1813-1818 (1999).

96. Subasinghe, N. L. et al. A novel series of pyrazolylpiperidine $\mathrm{N}$-type calcium channel blockers. Bioorg. Med. Chem. Lett. 22, 4080-4083 (2012).

97. Shao, P. P. et al. Aminopiperidine sulfonamide $\mathrm{Ca}_{\mathrm{v}} 2.2$ channel inhibitors for the treatment of chronic pain. J. Med. Chem. 55, 9847-9855 (2012).

98. Hu, L. Y. et al. Synthesis and biological evaluation of substituted 4-(OBz)phenylalanine derivatives as novel N-type calcium channel blockers. Bioorg. Med. Chem. Lett. 9, 1121-1126 (1999).

99. Yamamoto, T. et al. Discovery and evaluation of selective $\mathrm{N}$-type calcium channel blockers: 6-unsubstituted1,4-dihydropyridine-5-carboxylic acid derivatives. Bioorg. Med. Chem. Lett. 22, 3639-3642 (2012)

100. Scott, V. E. et al. A-1048400 is a novel, orally active state-dependent neuronal calcium channel blocker that produces dose-dependent antinociception without altering hemodynamic function in rats. Biochem. Pharmacol. 83, 406-418 (2012).

101. Cheng, J. K., Lin, C. S., Chen, C. C., Yang, J. R. \& Chiou, L. C. Effects of intrathecal injection of T-type calcium channel blockers in the rat formalin test. Behav. Pharmacol. 18, 1-8 (2007).

102. Bourinet, E. et al. Silencing of the Ca 3.2 T-type calcium channel gene in sensory neurons demonstrates its major role in nociception. $E M B O \mathrm{~J}$. 24, 315-324 (2005)

This paper demonstrates that in vivo siRNA knockdown of Cav3.2 channels mediates analgesia in inflammatory and neuropathic pain models, thus validating these channels as important drug targets for pain.

103. Berger, N. D. et al. NMP-7 inhibits chronic inflammatory and neuropathic pain via block of Cav3.2 T-type calcium channels and activation of CB2 receptors. Mol. Pain 10, 77 (2014).

104. Bladen, C. et al. Characterization of novel cannabinoid based T-type calcium channel blockers with analgesic effects. ACS Chem. Neurosci. 6, 277-287 (2015).

105. Gadotti, V. M. et al. Analgesic effect of a mixed T-type channel inhibitor/CB2 receptor agonist. Mol. Pain 9, 32 (2013)

106. Bladen, C. et al. 1,4-dihydropyridine derivatives with T-type calcium channel blocking activity attenuate inflammatory and neuropathic pain. Pflugers Arch. 467, 1237-1247 (2014)

107. Lee, M. J. et al. KST5468, a new T-type calcium channel antagonist, has an antinociceptive effect on inflammatory and neuropathic pain models. Pharmacol. Biochem. Behav. 97, 198-204 (2010).

108. Choe, W. et al. TTA-P2 is a potent and selective blocker of T-type calcium channels in rat sensory neurons and a novel antinociceptive agent. Mol. Pharmacol. 80, 900-910 (2011)

109. Chemin, J., Monteil, A., Perez-Reyes, E., Nargeot, J. \& Lory, P. Direct inhibition of T-type calcium channels by the endogenous cannabinoid anandamide. $E M B O \mathrm{~J}$. 20, 7033-7040 (2001)

110. Gilmore, A. J., Heblinski, M., Reynolds, A., Kassiou, M. \& Connor, M. Inhibition of human recombinant T-type calcium channels by $\mathrm{N}$-arachidonoyl 5-HT. Br. J. Pharmacol. 167, 1076-1088 (2012).

111. Hildebrand, M. E. et al. A novel slow-inactivation specific ion channel modulator attenuates neuropathic pain. Pain 152, 833-843 (2011)

112. Lee, M. Z944: a first in class T-type calcium channe modulator for the treatment of pain. J. Peripher Nerv. Syst. 19 (Suppl. 2), 11-12 (2014)

113. Ziegler, D., Duan, W. R., An, G., Thomas, J. W. \& Nothaft, W. A randomized double-blind, placeboand active-controlled study of T-type calcium channel blocker ABT-639 in patients with diabetic peripheral neuropathic pain. Pain 156, 2013-2020 (2015)

114. Terashima, T., Xu, Q., Yamaguchi, S. \& Yaksh, T. L. Intrathecal $\mathrm{P} / \mathrm{Q}^{-}$and $\mathrm{R}$-type calcium channel blockade of spinal substance $P$ release and c-Fos expression. Neuropharmacology 75, 1-8 (2013)

115. Matthews, E. A., Bee, L. A., Stephens, G. J. $\delta$ Dickenson, A. H. The Ca 2.3 calcium channe antagonist SNX-482 reduces dorsal horn neuronal responses in a rat model of chronic neuropathic pain. Eur. J. Neurosci. 25, 3561-3569 (2007).

116. Murakami, M. et al. Antinociceptive effect of different types of calcium channel inhibitors and the distribution of various calcium channel $\alpha$, subunits in the dorsal horn of spinal cord in mice. Brain Res. 1024, 122-129 (2004). 
117. Saegusa, H. et al. Altered pain responses in mice lacking $\alpha_{1 E}$ subunit of the voltage-dependent $\mathrm{Ca}^{2+}$ channel. Proc. Natl Acad. Sci. USA 97, 6132-6137 (2000).

118. Bourinet, E. et al. Interaction of SNX482 with domains III and IV inhibits activation gating of $\alpha_{1 E}$ (Ca 2.3) calcium channels. Biophys. J. 81, 79-88 (2001).

119. Ide, S. et al. Association between genetic polymorphisms in $\mathrm{Ca}_{\mathrm{v}} 2.3$ (R-type) $\mathrm{Ca}^{2+}$ channels and fentanyl sensitivity in patients undergoing painful cosmetic surgery. PLOS ONE 8, e70694 (2013)

120. Herman, S. T. Epilepsy after brain insult: targeting epileptogenesis. Neurology 59, S21-S26 (2002).

121. Blumenfeld, H. Cellular and network mechanisms of spike-wave seizures. Epilepsia 46 (Suppl. 9), 21-33 (2005).

122. Noebels, J. L. The biology of epilepsy genes. Annu. Rev. Neurosci. 26, 599-625 (2003).

123. Heron, S. E., Scheffer, I. E., Berkovic, S. F., Dibbens, L. M. \& Mulley, J. C. Channelopathies in idiopathic epilepsy. Neurotherapeutics 4, 295-304 (2007).

124. Khosravani, H. \& Zamponi, G. W. Voltage-gated calcium channels and idiopathic generalized epilepsies. Physiol. Rev. 86, 941-966 (2006).

125. Luttjohann, A. \& van Luijtelaar, G. Dynamics of networks during absence seizure's on- and offset in rodents and man. Front. Physiol. 6, 16 (2015).

126. Cheong, E. \& Shin, H. S. T-type $\mathrm{Ca}^{2+}$ channels in absence epilepsy. Pflugers Arch. 466, 719-734 (2014).

127. Tscherter, A. et al. Minimal alterations in T-type calcium channel gating markedly modify physiological firing dynamics. J. Physiol. $\mathbf{5 8 9}$ 1707-1724 (2011).

128. Song, l. et al. Role of the $\alpha 1 \mathrm{G}$ T-type calcium channel in spontaneous absence seizures in mutant mice. J. Neurosci. 24, 5249-5257 (2004) This paper reveals an upregulation of T-type calcium channels in several mouse models of epilepsy, and shows that deletion of Cav3.1 channels protects from absence seizures.

129. Powell, K. L. et al. A Ca 3.2 T-type calcium channel point mutation has splice-variant-specific effects on function and segregates with seizure expression in a polygenic rat model of absence epilepsy. J. Neurosci. 29, 371-380 (2009)

This important paper reveals that Cav3.2 mutations linked to epilepsy manifest their physiological effects in a channel splice isoform-dependent manner.

130. Zamponi, G. W., Lory, P. \& Perez-Reyes, E. Role of voltage-gated calcium channels in epilepsy. Pflugers Arch. 460, 395-403 (2010)

131. Heron, S. E et al. Extended spectrum of idiopathic generalized epilepsies associated with $\mathrm{CACNA} 1 \mathrm{H}$ functional variants. Ann. Neurol. 62, 560-568 (2007)

132. Khosravani, H. et al. Gating effects of mutations in the Cav3.2 T-type calcium channel associated with childhood absence epilepsy. J. Biol. Chem. 279, 9681-9684 (2004).

133. Vitko, I. et al. The I-II loop controls plasma membrane expression and gating of $\mathrm{Ca}_{v} 3.2 \mathrm{~T}$-type $\mathrm{Ca}^{2+}$ channels: a paradigm for childhood absence epilepsy mutations. J. Neurosci. 27, 322-330 (2007).

134. Eckle, V. S. et al. Mechanisms by which a CACNA1H mutation in epilepsy patients increases seizure susceptibility. J. Physiol. 592, 795-809 (2014).

135. Ernst, W. L., Zhang, Y., Yoo, J. W., Ernst, S. J \& Noebels, J. L. Genetic enhancement of thalamocortical network activity by elevating $\alpha 1$ g-mediated low-voltage-activated calcium current induces pure absence epilepsy. J. Neurosci. 29, 1615-1625 (2009).

136. Kim, D. et al. Lack of the burst firing of thalamocortical relay neurons and resistance to absence seizures in mice lacking $\alpha_{1 \mathrm{C}}$ T-type $\mathrm{Ca}^{2}$ channels. Neuron 31, 35-45 (2001).

137. Cain, S. M. \& Snutch, T. P. Contributions of T-type calcium channel isoforms to neuronal firing. Channels 4, 475-482 (2010).

138. Astori, S. et al. The Ca 3.3 calcium channel is the major sleep spindle pacemaker in thalamus. Proc. Nat Acad. Sci. USA 108, 13823-13828 (2011).

139. Lee, S. E. et al. Rebound burst firing in the reticular thalamus is not essential for pharmacological absence seizures in mice. Proc. Natl Acad. Sci. USA 111 11828-11833 (2014).

140. Huguenard, J. R. Block of T-type $\mathrm{Ca}^{2+}$ channels is an important action of succinimide antiabsence drugs. Epilepsy Curr. 2, 49-52 (2002).
141. Gomora, J. C., Daud, A. N., Weiergraber, M. \& Perez-Reyes, E. Block of cloned human T-type calcium channels by succinimide antiepileptic drugs. Mol. Pharmacol. 60, 1121-1132 (2001).

142. Todorovic, S. M. \& Lingle, C. J. Pharmacological properties of $\mathrm{T}$-type $\mathrm{Ca}^{2+}$ current in adult rat sensory neurons: effects of anticonvulsant and anesthetic agents. J. Neurophysiol. 79, 240-252 (1998).

143. Ziyatdinova, S. et al. Spontaneous epileptiform discharges in a mouse model of Alzheimer's disease are suppressed by antiepileptic drugs that block sodium channels. Epilepsy Res. 94, 75-85 (2011).

144. Gottlicher, M. et al. Valproic acid defines a novel class of HDAC inhibitors inducing differentiation of transformed cells. EMBO J. 20, 6969-6978 (2001).

145. Matar, N. et al. Zonisamide block of cloned human T-type voltage-gated calcium channels. Epilepsy Res. 83, 224-234 (2009).

146. Tanabe, M., Murakami, T. \& Ono, H. Zonisamide suppresses pain symptoms of formalin-induced inflammatory and streptozotocin-induced diabetic neuropathy. J. Pharmacol. Sci. 107, 213-220 (2008).

147. Tringham, E. et al. T-type calcium channel blockers that attenuate thalamic burst firing and suppress absence seizures. Sci. Transl. Med. 4, 121 ra19 (2012). This elegant paper identifies novel T-type calcium channel blockers and assesses their efficacy in seizure models.

148. Johannessen Landmark, C., Beiske, G., Baftiu, A., Burns, M. L. \& Johannessen, S. I. Experience from therapeutic drug monitoring and gender aspects of gabapentin and pregabalin in clinical practice. Seizure 28, 88-91 (2015).

149. Iyer, A. \& Marson, A. Pharmacotherapy of focal epilepsy. Expert Opin. Pharmacother. 15, 1543-1551 (2014)

150. Glauser, T. A. et al. Ethosuximide, valproic acid, and lamotrigine in childhood absence epilepsy: initial monotherapy outcomes at 12 months. Epilepsia $\mathbf{5 4}$ 141-155 (2013).

151. Hainsworth, A. H., McNaughton, N. C., Pereverzev, A. Schneider, T. \& Randall, A. D. Actions of sipatrigine, 202W92 and lamotrigine on R-type and T-type $\mathrm{Ca}^{2+}$ channel currents. Eur. J. Pharmacol. 467, 77-80 (2003)

152. Dibue, M. et al. Ca 2.3 (R-type) calcium channels are critical for mediating anticonvulsive and neuroprotective properties of lamotrigine in vivo. Epilepsia 54, 1542-1550 (2013).

153. Kuzmiski, J. B., Barr, W., Zamponi, G. W. \& MacVicar, B. A. Topiramate inhibits the initiation of plateau potentials in CA 1 neurons by depressing R-type calcium channels. Epilepsia 46, 481-489 (2005).

154. Radzicki, D. et al. Temperature-sensitive Cav1.2 calcium channels support intrinsic firing of pyramidal neurons and provide a target for the treatment of febrile seizures. J. Neurosci. 33, 9920-9931 (2013).

155. Furukawa, T. et al. Five different profiles of dihydropyridines in blocking T-type $\mathrm{Ca}^{2+}$ channe subtypes ( $\mathrm{Ca}_{3} 3.1\left(\alpha_{1 \mathrm{c}}\right), \mathrm{Ca} 3.2\left(\alpha_{14}\right)$, and $\left.\mathrm{Ca}_{v} 3.3\left(\alpha_{1}\right)\right)$ expressed in Xenopus oocytes. Eur. J. Pharmacol. 613, 100-107 (2009).

156. Sirven, J. I., Noe, K., Hoerth, M. \& Drazkowski, J. Antiepileptic drugs 2012: recent advances and trends. Mayo Clin. Proc. 87, 879-889 (2012).

157. Sulzer, D. \& Surmeier, D. J. Neuronal vulnerability, pathogenesis, and Parkinson's disease. Mov. Disord. 28, 715-724 (2013).

158. Zahodne, L. B. \& Fernandez, H. H. Pathophysiology and treatment of psychosis in Parkinson's disease: a review. Drugs Aging 25, 665-682 (2008).

159. Connolly, B. S. \& Lang, A. E. Pharmacological treatment of Parkinson disease: a review. JAMA 311, 1670-1683 (2014)

160. Kalia, L. V., Kalia, S. K., McLean, P. J., Lozano, A. M. $\&$ Lang, A. E. $\alpha$-synuclein oligomers and clinical implications for Parkinson disease. Ann. Neurol. 73, 155-169 (2013).

161. Nuytemans, K., Theuns, J., Cruts, M. \& Van Broeckhoven, C. Genetic etiology of Parkinson disease associated with mutations in the SNCA, PARK2, PINK 1, PARK7, and LRRK2 genes: a mutation update. Hum. Mutat. 31, 763-780 (2010)

162. Abdel-Salam, O. M. The paths to neurodegeneration in genetic Parkinson's disease. CNS Neurol. Disord. Drug Targets 13, 1485-1512 (2014).

163. Putzier, I., Kullmann, P. H., Horn, J. P. \& Levitan, E. S $\mathrm{Ca}_{\mathrm{v}} 1.3$ channel voltage dependence, not $\mathrm{Ca}^{2+}$ selectivity, drives pacemaker activity and amplifies bursts in nigral dopamine neurons. J. Neurosci. 29 15414-15419 (2009).
164. Guzman, J. N., Sánchez-Padilla, J., Chan, C. S. ¿ Surmeier, D. J. Robust pacemaking in substantia nigra dopaminergic neurons. J. Neurosci. 29, 11011-11019 (2009).

165. Chan, C. S., Gertler, T. S. \& Surmeier, D. J. A molecular basis for the increased vulnerability of substantia nigra dopamine neurons in aging and Parkinson's disease. Mov. Disord. 25 (Suppl. 1), 63-70 (2010)

166. Guzman, J. N. et al. Oxidant stress evoked by pacemaking in dopaminergic neurons is attenuated by DJ-1. Nature 468, 696-700 (2010).

This important study links pacemaker activity in dopaminergic substantia nigra neurons to L-type calcium channel-mediated increases in oxidative stress and cell damage.

167. Hurley, M. J., Brandon, B., Gentleman, S. M. \& Dexter, D. T. Parkinson's disease is associated with altered expression of $\mathrm{Ca}_{\mathrm{v}} 1$ channels and calciumbinding proteins. Brain 136, 2077-2097 (2013).

168. Dragicevic, E. et al. Ca 1.3 channels control D2-autoreceptor responses via NCS-1 in substantia nigra dopamine neurons. Brain 137, 2287-2302 (2014).

169. Anzalone, A. et al. Dual control of dopamine synthesis and release by presynaptic and postsynaptic dopamine D2 receptors. J. Neurosci. 32, 9023-9034 (2012).

170. Parkinson Study Group. Phase II safety, tolerability, and dose selection study of isradipine as a potential disease-modifying intervention in early Parkinson's disease (STEADY-PD). Mov. Disord. 28, 1823-183 (2013).

This clinical trial supports the administration of the L-type channel blocker isradipine as a possible therapeutic strategy for Parkinson disease.

171. Striessnig, J., Pinggera, A., Kaur, G., Bock, G. \& Tuluc, P. L-type $\mathrm{Ca}^{2+}$ channels in heart and brain Wiley Interdiscip. Rev. Membr. Transp. Signal 3, 15-38 (2014).

172. Kang, S. et al. Ca 1.3-selective L-type calcium channel antagonists as potential new therapeutics for Parkinson's disease. Nat. Commun. 3, 1146 (2012).

173. Huang, $\mathrm{H}$. et al. Modest $\mathrm{Ca}_{\mathrm{v}} 1.342$-selective inhibition by compound 8 is $\beta$-subunit dependent. Nat. Commun. 5, $4481(2014)$

174. Ortner, N. J. et al. Pyrimidine-2,4,6-triones are a new class of voltage-gated L-type $\mathrm{Ca}^{2+}$ channel activators. Nat. Commun. 5, 3897 (2014).

175. Tai, C. H., Yang, Y. C., Pan, M. K., Huang, C. S. \& Kuo, C. C. Modulation of subthalamic T-type $\mathrm{Ca}^{2+}$ channels remedies locomotor deficits in a rat model of Parkinson disease. J. Clin. Invest. 121, 3289-3305 (2011)

176 Scott, C. K., Dennis, M. L., Laudet, A., Funk, R. R. \& Simeone, R. S. Surviving drug addiction: the effect of treatment and abstinence on mortality. Am. J. Publ. Health 101, 737-744 (2011).

177. Buttner, A. Review: the neuropathology of drug abuse. Neuropathol. Appl. Neurobiol. 37, 118-134 (2011)

178. Fowler, J. S., Volkow, N. D., Kassed, C. A. \& Chang, L. Imaging the addicted human brain. Sci. Pract. Perspect. 3, 4-16 (2007)

179. Nestler, E. J. The neurobiology of cocaine addiction. Sci. Pract. Perspect. 3, 4-10 (2005).

180. Kosten, T. R. $\&$ George, T. P. The neurobiology of opioid dependence: implications for treatment. Sci. Pract. Perspect. 1, 13-20 (2002).

181. Pierce, R. C. \& Kumaresan, V. The mesolimbic dopamine system: the final common pathway for the reinforcing effect of drugs of abuse? Neurosci. Biobehav Rev. 30, 215-238 (2006).

182. Chen, B. T., Hopf, F. W. \& Bonci, A. Synaptic plasticity in the mesolimbic system: therapeutic implications for substance abuse. Ann. NY Acad. Sci. 1187, 129-139 (2010).

183. Adinoff, B. Neurobiologic processes in drug reward and addiction. Harv. Rev. Psychiatry 12, 305-320 (2004).

184. Koob, G. F. \& Volkow, N. D. Neurocircuitry of addiction. Neuropsychopharmacology 35, 217-238 (2010).

185. Rosse, R. B. et al. Nimodipine pharmacotherapeutic adjuvant therapy for inpatient treatment of cocaine dependence. Clin. Neuropharmacol. 17, 348-358 (1994).

186. Reimer, A. R. \& Martin-Iverson, M. T. Nimodipine and haloperidol attenuate behavioural sensitization to cocaine but only nimodipine blocks the establishment of conditioned locomotion induced by cocaine. Psychopharmacol. 113, 404-410 (1994). 
187. Pierce, R. C., Quick, E. A., Reeder, D. C., Morgan, Z R. $\&$ Kalivas, P. W. Calcium-mediated second messengers modulate the expression of behavioral sensitization to cocaine. J. Pharmacol. Exp. Ther. 286, 1171-1176 (1998).

188. De Beun, R., Schneider, R., Klein, A., Lohmann, A. \& De Vry, J. Effects of nimodipine and other calcium channel antagonists in alcohol-preferring AA rats. Alcohol 13, 263-271 (1996).

189. Giordano, T. P., Satpute, S. S., Striessnig, J., Kosofsky, B. E. \& Rajadhyaksha, A. M. Up-regulation of dopamine $D_{2} L$ mRNA levels in the ventral tegmental area and dorsal striatum of amphetamine-sensitized C57BL/6 mice: role of Ca $1.3 \mathrm{~L}$-type $\mathrm{Ca}^{2+}$ channels. J. Neurochem. 99, 1197-1206 (2006).

190. Giordano, T. P. et al. Molecular switch from L-type $\mathrm{Ca}_{v} 1.3$ to $\mathrm{Ca}_{v} 1.2 \mathrm{Ca}^{2+}$ channel signaling underlies long-term psychostimulant-induced behavioral and molecular plasticity. J. Neurosci. 30, 17051-17062 (2010).

This paper elegantly links L-type calcium channels to drug addiction.

191. Schierberl, K. et al. Ca 1.3 L-type $\mathrm{Ca}^{2+}$ channels mediate long-term adaptation in dopamine D2L-mediated GluA1 trafficking in the dorsal striatum following cocaine exposure Channels 6, 11-17 (2012).

192. Schierberl, K. et al. $\mathrm{Ca}_{\mathrm{v}} 1.2 \mathrm{~L}$-type $\mathrm{Ca}^{2+}$ channels mediate cocaine-induced GluA 1 trafficking in the nucleus accumbens, a long-term adaptation dependent on ventral tegmental area $\mathrm{Ca}_{v} 1.3$ channels. J. Neurosci. 31, 13562-13575 (2011).

193. Rajadhyaksha, A. et al. L-type $\mathrm{Ca}^{2+}$ channels mediate adaptation of extracellular signal-regulated kinase $1 / 2$ phosphorylation in the ventral tegmental area after chronic amphetamine treatment. J. Neurosci. 24 7464-7476 (2004)

194. Liu, Y. et al. Ca 1.2 and $\mathrm{Ca}_{v} 1.3 \mathrm{~L}$-type calcium channels regulate dopaminergic firing activity in the mouse ventral tegmental area. J. Neurophysiol. 112 , 1119-1130 (2014)

195. Shulman, A., Jagoda, J., Laycock, G. \& Kelly, H. Calcium channel blocking drugs in the management of drug dependence, withdrawal and craving. A clinical pilot study with nifedipine and verapamil. Aust. Fam. Physician 27 (Suppl. 1), 19-24 (1998).

196. Jimenez-Lerma, J. M. et al. Nimodipine in opiate detoxification: a controlled trial. Addiction $\mathbf{9 7}$, 819-824 (2002)

197. Newton, P. M. et al. A blocker of N- and T-type voltagegated calcium channels attenuates ethanol-induced intoxication, place preference, self-administration, and reinstatement. J. Neurosci. 28, 11712-11719 (2008) This paper links the blockade of T-type and N-type channels to relief from alcohol addiction.

198. Bhutada, P. et al. Cilnidipine, an L/N-type calcium channel blocker prevents acquisition and expression of ethanol-induced locomotor sensitization in mice. Neurosci. Lett. 514, 91-95 (2012).

199. Ferreira, M. A. et al. Collaborative genome-wide association analysis supports a role for ANK3 and CACNA1C in bipolar disorder. Nat. Genet. 40, 1056-1058 (2008). This important study identifies Cav1.2 channels as a risk factor in psychiatric disorders.

200 Cross-Disorder Group of the Psychiatric Genomics Consortium. Identification of risk loci with shared effects on five major psychiatric disorders: a genomewide analysis. Lancet 381, 1371-1379 (2013).

201. Wang, F., Mclntosh, A. M., He, Y Gelernter, J \& Blumberg, H. P. The association of genetic variation in CACNA $1 C$ with structure and function of a frontotemporal system. Bipolar Disord. 13, 696-700 (2011)

202. Paulus, F. M. et al. Association of rs 1006737 in CACNA $1 C$ with alterations in prefrontal activation and fronto-hippocampal connectivity. Hum. Brain Mapp. 35, 1190-1200 (2014)

203. Erk, S. et al. Replication of brain function effects of a genome-wide supported psychiatric risk variant in the CACNA $1 C$ gene and new multi-locus effects. Neuroimage 94, 147-154 (2014).

204. Ament, S. A. et al. Rare variants in neuronal excitability genes influence risk for bipolar disorder Proc. Natl Acad. Sci. USA 112, 3576-3581 (2015)

205. Gershon, E. S. et al. A rare mutation of CACNA1C in a patient with bipolar disorder, and decreased gene expression associated with a bipolar-associated common SNP of CACNA1C in brain. Mol. Psychiatry 19, 890-894 (2014)
206. Yoshimizu, T et al. Functional implications of a psychiatric risk variant within CACNA1C in induced human neurons. Mol. Psychiatry 20, 284 (2015).

207. Ostacher, M. J. et al. Pilot investigation of isradipine in the treatment of bipolar depression motivated by genome-wide association. Bipolar Disord. 16, 199-203 (2014).

208. Splawski, l. et al. $\mathrm{Ca}_{\mathrm{v}} 1.2$ calcium channel dysfunction causes a multisystem disorder including arrhythmia and autism. Cell 119, 19-31 (2004).

This manuscript reports on the devastating effects of a de novo mutation in Cav1.2 channels in patients with Timothy syndrome.

209. Splawski, I. et al. Severe arrhythmia disorder caused by cardiac L-type calcium channel mutations. Proc. Natl Acad Sci. USA 102, 8089-8096; discussion 8086-8088 (2005)

210. Tian, Y. et al. Alteration in basal and depolarization induced transcriptional network in iPSC derived neurons from Timothy syndrome. Genome Med. 6 75 (2014).

211. Krey, J. F. et al. Timothy syndrome is associated with activity-dependent dendritic retraction in rodent and human neurons. Nat. Neurosci. 16, 201-209 (2013).

212. Pinggera, A. et al. CACNA1D de novo mutations in autism spectrum disorders activate Cav1.3 L-type calcium channels. Biol. Psychiatry 77, 816-822 (2015).

213. Breitenkamp, A. F. et al. Rare mutations of CACNB2 found in autism spectrum disease-affected families alter calcium channel function. PLOS ONE 9, e95579 (2014).

214. Lu, A. T., Dai, X., Martinez-Agosto, J. A. \& Cantor, R. M. Support for calcium channel gene defects in autism spectrum disorders. Mol. Autism 3, 18 (2012).

215. Splawski, l. et al. CACNA1H mutations in autism spectrum disorders. J. Biol. Chem. 281, 22085-22091 (2006)

216. Duval, E. R., Javanbakht, A. \& Liberzon, Neural circuits in anxiety and stress disorders: a focused review. Ther. Clin. Risk Manag 11, 115-126 (2015)

217. Fox, A. S., Oler, J. A., Tromp, D. P., Fudge, J. L. \& Kalin, N. H. Extending the amygdala in theories of threat processing. Trends Neurosci. 38, 319-329 (2015)

218. Felix-Ortiz, A. C. et al. BLA to vHPC inputs modulate anxiety-related behaviors. Neuron 79, 658-664 (2013)

219. Ricord, M. Academy of Medicine: Paris. Prov. Med. Surg. J. 2, 96-97 (1841)

220. Nasca, C. et al. Exposure to predator odor and resulting anxiety enhances the expression of the $\alpha_{2} \delta$ subunit of voltage-sensitive calcium channels in the amygdala. J. Neurochem. 125, 649-656 (2013).

221 Strawn, J. R. \& Geracioti, T. D. Jr. The treatment of generalized anxiety disorder with pregabalin an atypical anxiolytic. Neuropsychiatr. Dis. Treat. 3, 237-243 (2007)

222. Shinnick-Gallagher, P. McKernan, M. G Xie J \& Zinebi, F. L-type voltage-gated calcium channels are involved in the in vivo and in vitro expression of fear conditioning. Ann. NY Acad. Sci. 985, 135-149 (2003)

223. Lee, A. S. et al. Forebrain elimination of cacna 1 mediates anxiety-like behavior in mice. Mol. Psychiatry 17, 1054-1055 (2012).

224. Dao, D. T. et al. Mood disorder susceptibility gene CACNA1C modifies mood-related behaviors in mice and interacts with sex to influence behavior in mice and diagnosis in humans. Biol. Psychiatry 68, 801-810 (2010)

225. Fulga, I. G. \& Stroescu, V. Experimental research on the effect of calcium channel blockers nifedipine and verapamil on the anxiety in mice. Rom. J. Physiol. 34, 127-136 (1997)

226. Busquet, P. et al. $\mathrm{Ca}_{\mathrm{v}} 1.3 \mathrm{~L}$-type $\mathrm{Ca}^{2+}$ channels modulate depression-like behaviour in mice independent of deaf phenotype. Int. J. Neuropsychopharmacol. 13 499-513 (2010).

227. Saegusa, H. et al. Suppression of inflammatory and neuropathic pain symptoms in mice lacking the $\mathrm{N}$-type $\mathrm{Ca}^{2+}$ channel. EMBO J. 20, 2349-2356 (2001).

228. Cassidy, J. S., Ferron, L., Kadurin, I., Pratt, W. S. \& Dolphin, A. C. Functional exofacially tagged N-type calcium channels elucidate the interaction with auxiliary $\alpha_{2} \delta-1$ subunits. Proc. Natl Acad. Sci. USA 111, 8979-8984 (2014).
229. Murakami, M. et al. Modified behavioral characteristics following ablation of the voltage dependent calcium channel $\beta 3$ subunit. Brain Res. 1160, 102-112 (2007)

230. Lee, J. \& Shin, H. S. T-type calcium channels and thalamocortical rhythms in sleep: a perspective from studies of T-type calcium channel knockout mice CNS Neurol. Disord. Drug Targets 6, 63-69 (2007).

231. Amer, A. \& Maher, T. J. Nasal administration of the calcium channel blocker diltiazem decreases food intake and attenuates weight gain in rats. Pharmacol. Biochem. Behav. 82, 379-387 (2005).

232. Bell, T. J., Thaler, C., Castiglioni, A. J., Helton, T. D. \& Lipscombe, D. Cell-specific alternative splicing increases calcium channel current density in the pain pathway. Neuron 41, 127-138 (2004).

233. Altier, C. et al. Differential role of N-type calcium channel splice isoforms in pain. J. Neurosci. 27 6363-6373 (2007)

This study follows up on findings in reference 232 and shows that a unique Cav 2.2 splice variant that is selectively expressed in nociceptive fibres is critical for pain transmission.

234. Chang, S. Y. et al. Age and gender-dependent alternative splicing of P/Q-type calcium channel EF-hand. Neuroscience 145, 1026-1036 (2007).

235. Michailidis, I. E. et al. Age-related homeostatic midchannel proteolysis of neuronal L-type voltage-gated $\mathrm{Ca}^{2+}$ channels. Neuron 82, 1045-1057 (2014).

236. Schrauwen, I. et al. A mutation in CABP2, expressed in cochlear hair cells, causes autosomal-recessive hearing impairment. Am. J. Hum. Genet. 91 636-645 (2012)

237. Yang, P. S. et al. Switching of $\mathrm{Ca}^{2+}$-dependent inactivation of $\mathrm{Ca}_{v} 1.3$ channels by calcium binding proteins of auditory hair cells. J. Neurosci. 26, 10677-10689 (2006).

238. Kuryshev, Y. A., Brown, A. M., Duzic, E. \& Kirsch, G. E. Evaluating state dependence and subtype selectivity of calcium channel modulators in automated electrophysiology assays. Assay Drug Dev. Technol. 12, 110-119 (2014).

239. Brittain, J. M. et al. Suppression of inflammatory and neuropathic pain by uncoupling CRMP-2 from the presynaptic $\mathrm{Ca}^{2+}$ channel complex. Nat. Med. 17 822-829 (2011)

240. Garcia-Caballero, A. et al. The deubiquitinating enzyme USP5 modulates neuropathic and inflammatory pain by enhancing $\mathrm{Ca} 3.2$ channel activity. Neuron 83, 1144-1158 (2014). This study identifies deubiquitylation of Cav3.2 channels as a critical factor in the development of chronic pain, and shows that interfering with this process can be exploited to develop new analgesics.

241. Gadotti, V. M. et al. Small organic molecule disruptors of Cav3.2-USP5 interactions reverse inflammatory and neuropathic pain. Mol. Pain 11, 12 (2015).

242. Inagaki, A., Frank, C. A., Usachev, Y. M. Benveniste, M. \& Lee, A. Pharmacological correction of gating defects in the voltage-gated $\mathrm{Ca}_{v} 2.1 \mathrm{Ca}^{2+}$ channel due to a familial hemiplegic migraine mutation. Neuron 81, 91-102 (2014).

243. Fischer, T. Z. et al. A novel Na 1.7 mutation producing carbamazepine-responsive erythromelalgia. Ann. Neurol. 65, 733-741 (2009) The authors of this paper identify a sodium channe mutation in a patient with erythromelalgia, study the effect of the mutation in a recombinant expression system, and then use this information to design customized treatment of the patient.

\section{Acknowledgements}

G.W.Z. holds a Canada Research Chair, and work in his laboratory is supported by grants from the Canadian Institutes of Health Research, Alberta Innovates: Health Solutions, and the Natural Sciences and Engineering Research Council of Canada.

Competing interests statement

The author declares no competing interests.

\section{FURTHER INFORMATION}

Convergence Pharmaceuticals press release:

http://www.convergencepharma.com/userfiles/file/

944 Phase\%20II DPN\%20FINAL.pdf

ALL LINKS ARE ACTIVE IN THE ONLINE PDF 